\title{
Contribuições da Sociologia na América Latina à imaginação sociológica: análise, crítica e compromisso social
}

\section{JOSÉ VICENTE TAVARES-DOS-SANTOS E MAÍRA BAUMGARTEN}

Que no hay patria en que pueda tener el hombre más orgullo que en nuestras dolorosas repúblicas americanas (José Marti, 1891)

Uma viagem que é sempre busca e negação, reconhecimento e recriação (Octavio lanni, 1993).

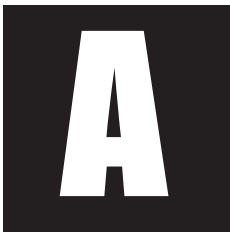

Sociologia expressou as profundas transformações das sociedades latino-americanas: acompanhou o processo de construção do Estado e da Nação, problematizou as questões sociais, analisou os efeitos da mundialização das conflitualidades, sempre se mantendo em um diálogo internacional múltiplo, pois "são importantes as possibilidades que se abrem com a pluralidade da interlocução. Multiplicam-se as perspectivas de reflexão e criação" (Ianni, 1993, p. 138). Os traços distintivos do saber sociológico no Continente foram: o internacionalismo, o hibridismo, a aborda-

\footnotetext{
* Doutor de Estado pela Université de Paris - Nanterre, Professor Titular do Departamento de Sociologia e do Programa de Pósgraduação em Sociologia do Instituto de Filosofia e Ciências Humanas da Universidade Federal do Rio Grande do Sul, Pesquisador do CNPq, Vice-Presidente da ALAS - Associação Latino-americana de Sociologia.

** Doutora em Sociologia, Professora do Departamento de Educação e Ciências do Comportamento da Fundação Universidade Federal de Rio Grande (FURG) e do Programa de Pós-graduação em Sociologia da Universidade Federal do Rio Grande do Sul (UFRGS). mayrab@terra.com.br
} 
gem crítica dos processos e conflitos das sociedades latino-americanas e o compromisso social do sociólogo. Ou seja, concordamos com lanni que a "cultura latino-americana está marcada por três tendências mais ou menos nítidas: colonialismo, nacionalismo e cosmopolitismo" (Ianni, 1993, p. 122).

Podemos identificar seis períodos na Sociologia na América Latina e no Caribe: I) a herança intelectual da Sociologia (Século XIX até início do Século XX); II) a Sociologia da cátedra (1890-1950); III) o período da "Sociologia Científica" e a configuração da "Sociologia Crítica" (1950-1973); IV) a crise institucional, a consolidação da "Sociologia Crítica" e a diversificação da Sociologia (1973-1983); V) a Sociologia do autoritarismo, da democracia e da exclusão (1983-2000); VI) a consolidação institucional e a mundialização da Sociologia da América Latina (desde o ano de 2000). ${ }^{1}$

\section{I - A herança intelectual da Sociologia (Século XIX até início do Século XX)}

A herança intelectual da Sociologia na América Latina foi configurada por autores que se preocuparam, nas primeiras décadas do Século XX, em realizar uma interpretação geral da sociedade na qual viviam. Podemos denominá-los de "pensadores sociais":

O Período dos Pensadores Sociais corresponde historicamente ao período que se estende das lutas pela Independência das nações latino-americanas até o início do século XX. Durante esse período, a (...) teoria social tendeu a ser elaborada por pensadores sob a influência de idéias filosófico-sociais européias ou nor-

\footnotetext{
1 “Segundo Germani (1959), a Sociologia na América Latina percorreu três momentos essenciais: a) Etapa do Pensamento PréSociológico, das Guerras de Independência até fins do Século XIX; b) Etapa das Cátedras (1890/1900-1950); e c) Etapa da Sociologia "Científica" (com início em 1950, aproximadamente) (Liedke Filho, 2003) (Cf. Germani, 1959; Chacon, 1977; lanni, 1989; Marini \& Millán, 1994; Castañeda Sabido, 2004).
} 
te-americanas como, por exemplo, o iluminismo francês, o ecletismo do Cousin, o positivismo do Comte e o evolucionismo do Spencer (Liedke Fo., 2003).

No Brasil, vivia-se um ambiente intelectual marcado pela Revolução Modernista de 1922, uma contemporaneidade de idéias, que foi aprofundada com as missões de professores estrangeiros, dos Estados Unidos e da França. Data dos anos 30 a publicação de algumas grandes obras: "Casa Grande e Senzala", de Gilberto Freyre, em 1933,2 "Evolução Política do Brasil", de Caio Prado Júnior, em 1933, ${ }^{3}$ e "Raízes do Brasil", de Sérgio Buarque da Holanda, em 1936. ${ }^{4}$ Tais "livros expressam um momento de discussão sobre a identidade e a formação da sociedade brasileira" (Barreira, 2004).

Em outros países da América Latina, também houve a importante contribuição dos pensadores sociais. No Chile, José Vitorino Lastarria (1817): "O Positivismo"; Valentin Letelier (1852-1919); Enrique Molina: "O Ensaio Moderno" (Brunner, 1988). No Peru, pode-se registrar José Carlos Mariátegui (1895-1930)5 e Victor Raúl Haya de la Torre (1895), "El Imperialismo y el PARA"; e José Miguel Arguedas. Em Cuba, Ramiro Guerra, com "Azúcar y población em las Antillas" (Sosa, 1994, in: Marina \& Millán, 1994).

Na Venezuela, Vallenilla Lanz escreveu o livro "Cesarismo democrático, estudio sobre las bases sociológicas de la Constitución efectiva de Venezuela" (1919); José Rafael Mendoza, "Ideológica y moral" (1938) e Rafael Caldeira, "Idea de una sociología venezolana" (1954) (Albornoz, 2001, p. 21, in: Romero Salazar, 2001). No México foram publicados: "Los Grandes Problemas Nacionales" de José Vasconcelos e Andrez Molina

\footnotetext{
2 Bastos, 2003; Kosminsky, 2003.

3 Rego, 2000; D’Incao, 1989.

4 Veloso \& Madeira, 1999.

5 Mariategui, Jose Carlos. 7 Ensayos de interpretación de la realidad peruana. Lima, Amauta, 27aㅗ ed. 1973; Bellotto \& Corrêa, 1982; Amayo \& Segatto, 2002; Cotler, 1982, p. 15.
} 
Henríquez; "Las Classes Sociales" de Mariano Otero e "Evolución Política del Pueblo Mexicano" de Justo Sierra. Na Argentina, ainda no Século XIX, "Facundo o Civilización y Barbarie", de Sarmiento (1811-1888) foi publicado em 1845.

O maior resultado da contribuição dos pensadores sociais foi a legitimação de um discurso sobre a sociedade, um discurso que também define uma posição do intelectual enquanto intérprete do significado da construção da sociedade nacional (Brunner, p. 337/34). Em outras palavras, "a formação do pensamento latino-americano pode ser vista como a história da idéia de América Latina", com um tema fundamental, a "questão nacional". De acordo com lanni (1993)

Esse é o desafio mais freqüente nas interpretações sobre civilização e barbárie, instabilidade política crônica, sociedade civil e Estado forte, raça cósmica, Nossa América, revolução burguesa, revolução socialista e outras. (...) A questão nacional diz respeito a como se forma e transforma a nação. Todavia "há várias nações na nação latino-americana" (p. 32-33, 35). ${ }^{6}$

\section{A "Sociologia da Cátedra" (1890-1950)}

A institucionalização acadêmica da Sociologia se deu mediante a denominada "Sociologia de Cátedra", período que se iniciou, de acordo com Liedke Fo.,

...nos países latino-americanos, de um modo geral, em fins do século XIX, quando as cátedras de Sociologia foram introduzidas em Faculdades de Filosofia, Direito e Economia. No Brasil, este período somente se ini- 
ciou na década de 1920, quando cátedras de Sociologia foram criadas em Escolas Normais. Esta etapa foi marcada pela publicação de manuais para o ensino de Sociologia, nos quais se procurava divulgar as idéias de cientistas sociais europeus e norte-americanos renomados, bem como as idéias sociológicas a respeito de problemas sociais como urbanização, emigração, analfabetismo e pobreza (2003).

No Brasil, na década de 1930, surgiram a Escola Livre de Sociologia e Política, em 1933, e a Faculdade de Filosofia, Ciências e Letras, da Universidade de São Paulo, no Estado de São Paulo, em 1934 (Barreira, 2004; Kantor, 2001). Na cidade de Rio de Janeiro, foi criada, na Universidade do Distrito Federal, em 1935, depois transformada em Faculdade Nacional de Filosofia, na Universidade do Brasil, em 1939 (Lippi, 1995, p. 242). Um dos grandes nomes deste período foi Fernando de Azevedo. ${ }^{7}$

Na Argentina, o Instituto de Sociologia da Faculdade de Filosofia e Letras da Universidade de Buenos Aires foi criado em 1940. Alfredo Poviña era a liderança intelectual do período, não obstante, a obra de Sergio Bagu, "Economía de la Sociedad Colonial", de 1949, foi um marco na interpretação da história latino-americana. ${ }^{8}$

No México, Lúcio Mendieta y Nuñez estimula a organização do Instituto de Investigaciones Sociales e começa a editar a Revista Mexicana de Sociologia.

No Uruguai, em 1951, foi fundada a Cátedra de Sociologia na "Facultad de Derecho y Ciencias Sociales", da "Universidad de la República", e outra, distinta, na "Facultad de Arquitectura", em 1952. Entre os

7 AZEVEDO, Fernando de. Princípios de Sociologia. S. P., Melhoramentos, 1951 (Ed. Mex. FCE). Para uma reconstituição deste período, cf. MICELI, 1989.

8 BAGU, Sergio. Economía de la sociedad colonial (ensayo de historia comparada de América Latina. México, Grijalbo, 1992 (Edición ampliada y actualizada). 
mais importantes sociólogos estavam Isaac Ganon ("Estructura Social del Uruguay", 1966) e Aldo Solari ("Sociología Rural") e, depois, o "Instituto de Ciencias Sociales', em 1958; também se forma o CLAEH - "Centro Latinoamericano de Economia Humana" (Facultad, 2000; Piñeiro, 1988; Filgueira, 1979).

No Chile, a "Facultad de Filosofía y Educación de la Universidad de Chile", foi organizada em 1931, sendo Astolfo Taipa um dos mais importantes sociólogos chilenos do período.

As primeiras cátedras de Sociologia, na Venezuela, foram fundadas na "Universidad Central", em 1902, e posteriormente na "Universidad de Los Andes". Posteriormente houve a criação do Departamento de Sociologia e Antropologia da "Universidad Central de Venezuela", no ano de 1953.

A criação da ALAS ocorreu no Primeiro Congresso Mundial de Sociologia, organizado pela ISA - "International Sociological Association", em Zurich, no ano de 1950. O I Congresso foi realizado em Buenos Aires, em 1951. Alfredo Poviña foi eleito presidente. O II Congresso foi realizado no Rio de Janeiro, em 1953, e Manuel Diegues Júnior foi o presidente eleito. Dois anos depois, em Quito, a preocupação do III Congresso da ALAS foi elaborar "un programa básico común para las Universidades latinoamericanas que contemplaba la siguiente división y organización de materias: historia de La sociología; lógica de La sociología; sociología general; sociologías especiales; sociología latinoamericana" (Brunner, p. 149).

Desde o I Congresso, já estavam presentes os concorrentes dos "sociólogos da cátedra", os componentes da futura "Sociologia Científica", como por exemplo, Gino Germani, com um trabalho apresentado em 1953, no Rio de Janeiro, em 1955, em Quito e em 1959, em Montevidéu (Germani, 2004, p. 133; Germani, 1971, p. 13).

No ano de 1957, em Santiago do Chile, efetivou-se o IV Congresso, no qual o sociólogo Astolfo Taipa foi eleito presidente da ALAS. Em 1959, no $V$ Congresso, em MONTEVIDEO, foi eleito Isaac Ganon. 
Pode-se afirmar que a etapa da "Sociologia da cátedra" possibilitou a institucionalização do discurso sociológico e a criação das escolas, faculdades e cursos de Sociologia ou de Ciências Sociais (Brunner, 1988, p. 347).

\section{III - O período da "Sociologia Científica" e a configuração da Sociologia Crítica (1950-1973)}

O período da "Sociologia Científica" foi marcado pela institucionalização acadêmica e pela problematização teórica ligada à investigação empírica, desde meados dos anos 50 até o final da década de 1960. Na Argentina, foi organizado o "Instituto de Sociología de la Universidad de Buenos Aires", no qual se configurou a "Sociologia Científica" com Gino Germani, Jorge Graciarena e Torquato Di Tella e, depois, a presença de Sergio Bagu e de Tulio Halperin Dongui.

No México, fundou-se a "Escuela Nacional de Ciencias Políticas y Sociales", na UNAM - "Universidad Nacional Autónoma de México", em 1951, e o "Centro de Estudios Latinoamericanos", em 1961.

No Brasil, nos anos 50 inicia-se a consolidação da "Escola de Sociologia da USP", protagonizada por Antonio Candido, Florestan Fernandes, Octavio lanni e Fernando Henrique Cardoso.

Essa escola viria a orientar a Sociologia brasileira por várias décadas. A evolução das orientações da obra de Florestan Fernandes (1920-1995), desde sua formação intelectual entre 1941 e 1952, é a grande expressão deste estilo de Sociologia na América Latina: foi a época de preocupação com a "Sociologia em uma era de revolução social" (1952-1967) (Liedke Fo. 2003b; Garcia, 2002; Nascimento; Candido, 2001). Também no Rio de Janeiro desenvolvia-se a Sociologia nas instituições universitárias:

O Estado de Rio de Janeiro, na metade do século passado, tem como principais expoentes nas Ciências Sociais: Hélio Jaguaribe, Nelson Werneck Sodré e Guer- 
reiro Ramos. Nos outros Estados da Federação, as Ciências Sociais vão também se estruturando, principalmente em Bahia, em Pernambuco, \{Rio Grande do Sul\} e em Minas Gerais, com profissionais egressos dos cursos de Direito e Economia, como também de Medicina, como é o caso do Thales do Azevedo, de Bahia (Barreira, 2004).

Figura exponencial desta época foi Guerreiro Ramos (1915-1982), cujo livro "A Redução Sociológica" (1958) marcou a Sociologia brasileira, ainda que tenha sido esquecido até recentemente (Lippi Oliveira, 1995). O livro propunha três sentidos para a "redução sociológica":

...redução como método de assimilação crítica da produção sociológica estrangeira. (...). 2) redução como atitude parentética, isto é, como adestramento cultural do indivíduo, que o habilita a transcender (...) os condicionamentos circunstanciais que conspiram contra a sua expressão livre e autônoma. (...). 3) redução como superação da Sociologia nos termos institucionais e universitários em que se encontra. A Sociologia é ciência por fazer (Ramos, 1965, p. 16).

A criação da CEPAL - Comissão Econômica para a América Latina, pelas Nações Unidas, em 1948, desencadeou a elaboração de um importante diagnóstico das economias latino-americanas, fundado em Raul Prebisch e em um conjunto de economistas e sociólogos:

En lo que respecta a los obstáculos externos, el cuestionamiento principal al libre funcionamiento del mercado se articuló en torno a la concepción centroperiferia y, en el interior de esa concepción, se centró en el deterioro de los términos de intercambio. La concepción centro-periferia (...) partía de reconocer la existencia de una división internacional del trabajo, 
en la cual los países latinoamericanos jugaban un papel subordinado y se especializaban en la producción y exportación de matérias primas y alimentos (...) (Estay Reino, 1994, p. 28, in: Marini \& Millán, 1994).

De acordo com Estay Reno, a concepção cepalina, analisando o âmbito interno das sociedades latino-americanas, afirmava: "la existencia de una 'heterogeneidad estructural' en las economías de la región, que resulta de una penetración desigual de la tecnología en los distintos sectores y, en particular, en la producción primaria y las actividades artesanales (...)" (1994, p. 30). Sobre a problemática agrária latino-americana, a CEPAL assinalava dois elementos: "a) la lentitud del crecimiento ligado a determinadas estructuras agrarias, y b) la estructura de la propiedad y tenencia de la tierra" (Giarraca, p. 78, in: Piñeiro, 2000).

A CEPAL congregou grandes economistas latino-americanos - Celso Furtado, Aníbal Pinto, Oswaldo Sunkel - e originou a criação do ILPES Instituto Latinoamericano de Planificación Económica y Social - em 1962, a partir do qual as teorias do desenvolvimento chegariam à planificação, mediante sucessivos cursos ministrados em Santiago do Chile e em outros países latino-americanos para formar os agentes do desenvolvimento.

No Chile, em 1951, foi criado o "Instituto de Investigaciones Sociológicas de la Facultad de Filosoíia y Educación de la Universidad de Chile", no qual Eduardo Hamuy teve importante papel. No ano de 1958, foi organizada a "Escuela de Sociología" e, no mesmo ano, começou a funcionar a "Escuela de Sociología de la Universidad Católica". Em ambas as instituições, uma renomada geração de sociólogos desenvolveu seus trabalhos, entre eles: Eduardo Hamuy, Hernán Godoy, Guillermo Briones, Rafael Baraona, Enzo Faletto, Danilo Salcedo, Edmundo Fuenzalida, Orlando Sepúlveda, Manuel Antonio Garreton, Roger Vekemans. Pode-se afirmar que

Es evidente la influencia del funcionalismo en cuanto 
orientación teórica, y el énfasis en las técnicas cuantitativas como orientación metodológica. El desideratum de la formación sociológica parecía consistir en la amalgama de las teorías de Parsons y de Merton con el dominio de las técnicas estadísticas (Godoy Urzúa, 1979, In Camacho, 1979, p. 519).

O apoio da UNESCO ao desenvolvimento das ciências sociais na América Latina materializou-se, neste período, em duas iniciativas. A primeira foi a criação do Centro Latino-americano de Pesquisas em Ciências Sociais, ${ }^{9}$ no Rio de Janeiro, em 1957, tendo como Diretor, até 1961, Luiz A. Costa Pinto. Vários sociólogos latino-americanos participaram de seminários na instituição: Gino Germani, Rodolfo Stavenhagen, Torquato Di Tella, Jorge Graciarena (Chor Maio, 1999, p. 35).

O Centro publicou a revista "América Latina", de 1959 até 1976, com um total de 251 artigos - dos quais 113 em espanhol e 76 em português, os restantes em inglês, 49, e francês, 13 - sendo a maioria sobre temas do desenvolvimento da América Latina e a respeito dos diferentes países (Lippi, 1995, p. 270-276). A principal produção se referia à Sociologia do desenvolvimento, da modernização e às "sociedades duais" (Lippi, 1995, p. 276/280). Seu final, em 1976, foi trágico: "com a anulação dos recursos do governo brasileiro, teve uma sobrevida e por fim fechou suas portas com episódios lamentáveis, como a entrega de sua biblioteca para o pagamento de uma dívida trabalhista (e a venda para reciclagem de papel)" (Lippi, 1995, p. 303-304).

A segunda iniciativa foi a fundação da FLACSO - Faculdade Latinoamericana de Ciências Sociais (1957) -, seu primeiro diretor foi José Medina Echevarría, cuja obra "Aspectos sociales del desarrollo económico" foi seminal (Echevarría, 1959). A expansão da FLACSO por uma dezena de países, nas décadas posteriores, foi responsável pela institucionalização das ciências sociais na América Latina durante os difíceis anos de regimes militares que marcariam o Continente a partir da década de 60.

9 Para maiores detalhes sobre o Centro ver o artigo de Lúcia Lippi Oliveira Diálogos intermitentes: relações entre Brasil e América Latina, neste dossiê. 
Na Colômbia, um grupo em torno de Orlando Fals Borda começa a produzir análises sociológicas, cujo marco foi a publicação de "La Violencia en Colombia" e, mais tarde, de "Las revoluciones inconclusas en América Latina" (Fals Borda, 1976, 1971).

$\mathrm{Na}$ Venezuela, começam a escrever J.A. Silva-Michelena e Orlando Albornoz. Na Guatemala, Severo Martinez Peláez publica, em 1970, "La Pátria del Criollo - ensayo de interpretación de la realidad colonial guatemalteca", obra de referência sobre as sociedades centro-americanas.

No México, Pablo González Casanova publica, em 1965, "La democracia en México", livro marco de uma abordagem sociológica orientada por uma perspectiva estrutural, analisando a formação do Estado Nacional com a noção de colonialismo interno (González Casanova, 1967). No Uruguai, foi fundado o "Instituto de Ciencias Sociales", na "Universidad de la República", em 1958.

Este período, entre 1950 e 1973, corresponde ao período das democracias populistas (Vargas, no Brasil (1950-1954); Perón, na Argentina (1945-1955), depois Frondizi (1955); no Chile, Ibánez (1952-1958), o liberalismo de Allessandri (1958-1964), a democracia cristã de Eduardo Frei (1964-1970); as poucas experiências de Governos Socialistas (Arbenz, na Guatemala,1948-1954; a mobilização na Republica Dominicana, em 1966; A Revolução Cubana, em 1959; no Chile, o Governo de Allende, entre 1970 e 1973).

Esta etapa da Sociologia Científica procurou,

sob a égide do paradigma estrutural-funcionalista, a institucionalização do ensino e da investigação em Sociologia, de modo análogo ao dos centros sociológicos dos países centrais. A concepção de desenvolvimento desta abordagem expressou-se na teoria da Modernização e na análise do processo de transição da sociedade tradicional para a sociedade moderna. (...) A Teoria da Modernização concebia o processo de 
desenvolvimento como uma transição de uma sociedade rural tradicional para uma sociedade industrial moderna (Germani, 1967).

Como afirma Liedke Fo, essa transição, quando incompleta, traz a coexistência de ambas as formas sociais dentro de uma mesma sociedade nacional, caracterizando-a como uma sociedade dual (2003).

Naqueles anos, os Congressos da ALAS foram realizados em vários países. Na Venezuela, em Caracas, em 1961. O presidente eleito do VI congresso foi o sociólogo Rafael Caldeira, e os principais temas abordados foram: "posibilidades y limitaciones de la investigación sociológica en América Latina"; "partidos políticos y Sociología electoral"; y "el cambio social en la América Latina" (Caldeira, 1961, p. 6-7). Em 1963, o VII Congresso foi efetivado em Bogotá; em 1967, realizou-se o VIII Congresso da ALAS.

No final deste período, iniciou-se a configuração da "Sociologia Crítica", a partir de uma análise questionadora dos pressupostos da Sociologia da modernização e da elaboração de uma abordagem construída por uma "interlocução múltipla" (lanni, 1993), com autores inconformistas dos Estados Unidos (tais como W. Mills, Horowitz) ou do marxismo heterodoxo francês (as incorporações de Henri Lefebvre e Jean Paul Sartre) e inglês (os primeiros trabalhos dos historiadores do Birbeck College, Londres, em torno de Eric Hobsbawm) (Hobsbawm, 2002).

Um dos principais sociólogos, neste período, foi Luiz Aguiar de Costa Pinto, diretor do Centro Latino-americano de Ciências Sociais de 1957 a 1961 e da Revista América Latina, tendo sido Vice-Presidente da Associação Internacional de Sociologia, de 1956 a 1959. A contribuição de Costa Pinto para a Sociologia deriva de sua concepção do trabalho sociológico como análise crítica da sociedade, tendo-se ele dedicado, com talento teórico e agudez na investigação empírica, à interpretação das relações 
raciais e das transições que marcaram as sociedades contemporâneas. Costa Pinto estudou a complexidade das relações raciais no Brasil e as possibilidades da sociedade brasileira em realizar uma transição para o desenvolvimento, com ênfase na análise da mudança social e cultural na sociedade brasileira, com aguçado olhar crítico e a busca do ideal de uma nova sociedade (Costa Pinto, 1970; Chor Maio \& Villas Bôas, 1999).

Em outras palavras, a institucionalização da Sociologia, neste período que finda em 1964, no caso do Brasil, "descortinou no horizonte da camada intelectual outra perspectiva interpretativa, baseada nas desigualdades sociais e econômicas inerentes à sociedade brasileira" (Villas Bôas, 1991, p. 37, in: Bomeny, Helena \& Birman, 1991).

Na Argentina, Jorge Graciarena já formulava, em 1967, os delineamentos de uma "Sociologia do conflito":

Neste tipo de perspectiva, a sociedade é vista como um sistema de forças em desequilíbrio e conflito permanente. (...) A sociedade é então uma unidade, mas uma unidade complexa formada por grande variedade de elementos cuja congruência e compatibilidade final é a conseqüência de um fato de força ou de poder, e que se traduz internamente pela dominação de uma classe sobre as outras classes sociais. (...) A Sociologia do conflito trata do desenvolvimento em nível mais histórico (...). A Sociologia do conflito o encara como um aspecto inseparável da dinâmica social, centrado na competição e na luta pela distribuição do poder e das recompensas sociais (Gracierena, 1971).

Estava em curso uma orientação crítica da "Sociologia da modernização", cujos expoentes foram Miguel Murmis, Juan Carlos Portantiero e a rede em torno de José Aricó, editor da Revista "Cuadernos de Pasado y Presente", a qual representou uma renovação do pensamento sociológico na América Latina (Murmis; Portantiero, 1974). 
Finalmente, foi criada a ALASRU - Asociación Latinoamericana de Sociología, em Buenos Aires, no ano de 1969, com o objetivo de "estimular la difusión y el perfeccionamiento de la Sociología Rural" (Nino Velásquez, 2000, p. 212, in Piñeiro, 2000), realizando seu I Congresso na República Dominicana em 1983 e o VI Congresso, em 2003 em Porto Alegre.

Estava cumprida a fase da institucionalização das ciências sociais na América Latina, com uma brilhante geração intelectual que foi dilapidada pelos golpes militares que se sucederam no Cone Sul, a partir de 1964 no Brasil, e na Argentina, em 1966 (Brunner, p. 351-356).

Todavia um processo intelectual estava em curso. Eliseo Verón, analisando a história recente da Sociologia na Argentina, revelava o início da crise da "Sociologia científica":

Por un lado, se produce una cierta diversificación ideológica (...). A partir de 1964, por ejemplo, la cátedra ya mencionada de Sociología Sistemática, que pasa a estar a cargo de Miguel Murmis y del autor de este trabajo, concede una importancia capital al pensamiento marxista, a la vez que introduce en la enseñanza orientaciones ajenas al estructural-funcionalismo (como la antropología estructural o la teoría de la comunicación) y corrientes no dominantes em la Sociología académica norteamericana (como Goffman, Garfinkel, Becker, etc.) (Verón, 1974, p. 45).

Em vários países da América Latina, a Sociologia renasceria e inclusive se manifestaria como uma "Sociologia crítica", muitas vezes no espaço de liberdade propiciado pelos Congressos da ALAS.

\section{A crise institucional, a consolidação da "Sociologia Críti- ca" e a diversificação da Sociologia (1973-1983)}


A diáspora de sociólogos do Brasil, da Argentina e do Uruguai começara. Em 1969, o IX Congresso da ALAS foi organizado no México, com a eleição de Pablo Gonzalez Casanova como presidente. A generosidade do povo mexicano contribuiu para a criação de instituições que acolheram muitos dos intelectuais exilados. Segundo Cueva,

Llegan a México sucesivas oleadas de exilados y emigrados latinoamericanos, de científicos sociales con alto nivel y experiencia. (...) Hecho que consecuentemente determina que ese país se convierta en los setentas en una especie de carrefour ideológico-cultural, marco inevitable de referencia para el quehacer científico y social (1985, p. 8-9, in Salles et alii, 1985).

Em 1971, foi criado o Centro de Estudos Sociológicos e, em 1973, o Programa de Doutorado em Sociologia do Colégio do México, além da UNAM, que continuava a ser a referência sob a égide de Pablo González Casanova.

Fato significativo foi a realização, em 1971, na Venezuela, do Congresso Mundial de Sociologia pelo Instituto Internacional de Sociologia, com a presença de importantes sociólogos, como Alwin Gouldner, Jean Duvignaud e Henri Chombart do Lowe.

Em 1972, na efervescência do Governo Allende, Guillermo Briones foi eleito presidente do X Congresso da ALAS. Este período, entre 1964 e 1983, corresponde ao período dos governos militares, com traços de autoritarismo e violência do Estado contra os opositores e contra muitos sociólogos (Brasil, 1964-1985; Argentina, 1966-1983; Chile, 1973-1989; Uruguai, 1973-1985).

No contexto dos golpes militares, na década de 60, houve o "Período de Crise e Diversificação da Sociologia latino-americana", a consolidação da "Sociologia Crítica" e a emergência da Teoria da Dependência, ao 
mesmo tempo em que se deu um duplo movimento: se, em vários países, se desencadeou uma crise institucional da Sociologia nas Universidades (em particular, no Uruguai, na Argentina e no Chile), em outros assistiu-se a uma consolidação institucional, como foi o caso do Brasil, na década de 1980, e do México. Segundo Andrade Carreño “El auge y generalización de las teorías de la dependencia, del marxismo y de la sociología crítica, en cambio, coincidieron con el momento de consolidación institucional, de expansión de la matrícula, y de la ampliación y diversificación acelerada de la infraestructura universitaria" (1996, in: Olivier, 1996, p. 80)

Neste período, em vários países, foram organizados centros de investigação, ocorrendo um processo de abertura de novas possibilidades institucionais para o trabalho sociológico. No Brasil, foram criados o CEBRAP, em 1970 e o CEDEC, em 1974. No Uruguai, o CIESU; no Chile, a FLACSO, o GIA - Grupo de Investigaciones Agrarios (GIA, 1991); no Peru, o CEP Centro de Estúdios Peruanos. Na Argentina, o Instituto Di Tella, o CICSO Centro de Investigaciones de Ciencias Sociales e o CEUR - Centro de Estudios Urbanos y Regionales.

Como conseqüência, houve a criação do CLACSO - Conselho Latino-americano de Ciências Sociais - em 1967, cuja função era coordenar esforços, representá-los na UNESCO e funcionar como agente de captação de recursos internacionais para os projetos a serem desenvolvidos pelos centros de investigação nos vários países latino-americanos, servindo, assim, para oferecer oportunidades de trabalho em ciências sociais, que asseguraram a continuidade da Sociologia na América Latina, fato marcante na História da Sociologia na América Latina, com a dedicação de seus secretários executivos, autores de importantes obras para a explicação crítica de nosso Continente: Francisco Delich, Fernando Calderón, Márcia Rivera e, desde os anos 90, Atílio Borón. ${ }^{10}$ 
A consolidação da "Sociologia Crítica" pode ser caracterizada pelas dimensões básicas compartilhadas por inúmeros cientistas sociais latinoamericanos (Florestan Fernandes, Octávio lanni, Orlando Fals Borda, Aníbal Quijano, Pablo Gonzalez Casanova, Fernando Henrique Cardoso, Enzo Faletto, Miguel Murmis, entre tantos outros): uma perspectiva de análise integrada; o método histórico-estrutural ou dialético; a consideração da historicidade do objeto de conhecimento; a análise dos fenômenos complexos de natureza internacional; a crítica radical do estrutural-funcionalismo; o interesse pelo marxismo como teoria totalizante para explicar a realidade da região; a temática do desenvolvimento e da mudança social e política (Franco, 1979, p. 271-284, in Camacho, 1979).

Deve-se agregar a enorme expansão da Sociologia Rural e dos processos sociais agrários na América Latina, os quais se orientaram pela perspectiva da Sociologia Crítica, desde os anos de 1960 (Pereira de Queiroz, 1973; Delich, 1970; Piñeiro, 1998 e 2000; Brumer e Tavares-Dos-Santos, in: Piñeiro, 2000; Giarraca, 1998 e 1999; Gia, 1991; Souza Martins, 1981; Tavares-Dos-Santos, 1991).

Houve, então, uma intensa discussão sobre as variantes do marxismo, desde o marxismo historicista da Escola da USP, ao marxismo althusseriano. Também foi o período de difusão internacional da teoria da dependência. Deve-se agregar, ainda, o marxismo endógeno, os neogramscianos, e o neodesenvolvimentismo (Marini \& Millán, 1995, p. 15).

Em outras palavras, "la 'Sociología Crítica' ubicó en el primer plano de la discusión el problema de la necesidad de la transformación práctica de la sociedad, vale decir, el problema de la revolución social" (Bobes León, 1990, p.32).

Um marco da "Sociologia Crítica" foi o livro de Heleieth Saffioti, "A mulher na sociedade de classes", publicado em 1969, cujo objetivo era "apreender os mecanismos típicos através dos quais o fator sexo opera nas 
sociedades de classes de modo a alijar da estrutura ocupacional grandes contingentes de elementos do sexo feminino" (Saffioti, 1969, p. 17). Ainda mais, talvez tenha sido das primeiras autoras na América Latina (inspirada em Marx e Simone de Beauvoir, parcialmente) a reconstituir a "mística feminina na era da ciência". Como afirma a própria Saffioti "a mística feminina tem-se, inúmeras vezes, nutrido de hipóteses e erros científicos, assim como das descobertas transfiguradas pela reinterpretação social que sofreram" (1969, p. 305). Enfim, o estudo propôs que a "explicação da situação da mulher na sociedade capitalista é encontrável através da análise das relações entre o fator natural sexo e as determinações essenciais do modo capitalista de produção" (Saffioti, 1969, p. 387).

Outros autores da segunda geração da "Escola de Sociologia da USP" começaram a publicar seus livros na década de 1980, entre eles: Marialice Forachhi, José César Gnacarini, Luiz Pereira, José de Souza Martins, Gabriel Cohn, Sedi Hirano.

No caso chileno, a produção das Ongs se caracterizou por "textos críticos", em função de uma postura de questionamento direto do governo militar. "A instituição produtora destes textos com maior grau de representatividade foi a FLACSO - Chile, pelo volume, periodicidade e influência social e científica de suas publicações: a esta pertence 'Un espejo trizado'"'11 (Alvarado \& Santander, 2003).

A reflexão de Norbert Lechner também corresponde a esta fase, pois o tema principal de sua obra foi "explorar la dimensión subjetiva de la política". (...) "Presumo que la política, al igual que las ciudades, está hecha de deseos y de miedos" (Lechner, 1988, p. 13).

Ao mesmo tempo, o autor assumia a conflitualidade da sociedade e a revalorização da sociedade civil (Lechner, 1988, p. 33-34), definindo, por conseqüência, como uma das tarefas centrais do processo de demo-

11 O livro "Un espejo trizado" foi escrito por Brunner, 1988. 
cratização - escrevendo ainda no regime militar - uma mudança na cultura política, a partir da própria vida cotidiana vinculada às diferenças na estrutura social (Lechner, 1988, p. 40; p. 50; p. 62; p. 64): "en segundo lugar, cabe vincular el interés por la vida cotidiana a un descontento más general: el descontento con las formas habituales de hacer política" (Lechner, 1988, p. 60).

Lechner repõe, à época, o debate entre autoritarismo e democratização no plano das representações simbólicas: os medos reais e invisíveis, a insegurança e a sociedade vigiada, a construção da ordem democrática e a confiança:

Quién tiene miedo y de qué? Entendiendo por miedo la percepción de una amenaza, real o imaginaria, propongo explorar los miedos bajo el autoritarismo en las sociedades latinoamericanas del Cono Sul. (...) Qué percibe la gente como una amenaza vital? En primer lugar, desde luego, toda amenaza a la integridad física (asesinato, tortura, asalto). En segundo lugar, lo que pone en peligro las condiciones materiales de vida (pobreza, desocupación, inflación, etcétera). (...)Junto a los miedos visibles existen miedos ocultos, apenas verbalizados (...) Una angustia, ese miedo difuso sin objeto determinado, corroe todo; se desmoronan las esperanzas, se desvanecen las emociones, se apaga la vitalidad (Lechner, 1988, p. 95/96).

Finalmente o autor evoca a necessidade da utopia, pois: "La utopía de la democracia es la autodeterminación de un pueblo sobre sus condiciones y modos de vida" (Lechner, 1988, p. 16).

Entretanto, durante os regimes militares no Cone Sul, houve repressão brutal e o exílio de sociólogos para o Chile primeiro, depois para o México e América Central e Caribe. A diáspora na Sociologia da América Latina produziu, paradoxalmente, um inédito processo de intercâmbio e diálogo acadêmico, tendo havido um deslocamento dos Congressos da ALAS para a América Andina e para a América Central. 
Em 1974, foi realizado o XI Congresso da ALAS em San José da Costa Rica, tendo sido eleito presidente Daniel Camacho (Camacho, 1979). O debate principal aconteceu entre duas abordagens da América Latina: "la discusión entre los autores que se colocan dentro del enfoque que gira alrededor del concepto de imperialismo con aquellos que utilizan preferentemente la categoría de la dependencia" (Camacho, 1979, p. 12).

Seguiu-se o XI Congresso da ALAS, em Quito, com a eleição de Agustín Cueva como seu presidente. Em 1979, na Ciudad de Panamá, Marco A. Gandásegui foi eleito presidente do XII Congresso da ALAS. Dois anos depois, em 1981, o XIII Congresso da ALAS, efetivado em San Juan de Porto Rico elegeu presidente a Denis Maldonado.

O XV Congresso da ALAS foi organizado em 1983, em Manágua, em plena Revolução Sandinista (1979-1990), cuja declaração final expressava a conjuntura da América Central:

La Revolución popular Sandinista es la culminación de la larga lucha antiimperialista del pueblo nicaragüense, por rescatar su soberanía y construir un orden social justo. (...) La voluntad de paz del gobierno y el pueblo de Nicaragua son plenamente evidentes. (...) Reconocemos al F.N.L.N. - PDR como el genuino representante de los intereses y aspiraciones del pueblo salvadoreño y ratificamos que la única alternativa de solución al grave conflicto que agobia a ese hermano país, es a través de una solución política negociada, en base a cambios profundos en las estructuras políticas, económicas y sociales en la actual sociedad salvadoreña. (...) Nos identificamos plenamente con las luchas que desarrolla desde hace varias décadas, el heroico pueblo guatemalteco que desde 1954 ha venido enfrentando a las dictaduras más oprobiosas de este Continente. (...) Los Científicos Sociales de nuestra América participantes en el XV Congreso Latinoamericano de Sociología, al aprobar esta 
Declaración de Managua, nos comprometemos en nuestra condición de intelectuales revolucionarios, a trabajar, modesta pero incansablemente, en favor del compromiso que en este evento hemos contraído. 'De América somos hijos' (Mattos \& Mato Grosso, 2005).

O ambiente no Congresso de Manágua manifestava uma esperança de superação das ditaduras. De acordo com Torres-Rivas:

Las formas autoritarias de gobierno se manifiestan, por ejemplo, en el control de la familia Somoza en Nicaragua durante más de cuarenta años (1937-1979) o en la permanencia durante medio siglo del Ejército en el gobierno de El Salvador (1931-1979). Y con otras características, los gobiernos militares que siguieron la caída de Arbenz, en Guatemala (1954-1982) (1993, p. 17).

A Revolução Sandinista (1979-1989), as guerras civis entre a guerrilha - FMLN e as guerrilhas com participação indígena - bem como, os governos autoritários em El Salvador e na Guatemala, produziram anseios de transformação social, mas foram sucedidas por acordos políticos, no primeiro caso, e pelos acordos de paz desencadeados pelo Grupo Contadora, deixando largas esperanças de mudança nas condições de vida dos povos da América Central (Figueroa Ibarra, 1993, in: Torres-Rivas, 1993, cap. 2).

Este foi o período de crise e diversificação da Sociologia latino-americana (1973-1983)

Caracterizado pela crise institucional e profissional da Sociologia sob a repressão político-cultural dos regimes autoritários e, simultaneamente, por uma profunda crise paradigmática, isto é, pela crise da hegemonia da Sociologia "Científica", com a emergência de alternativas teóricas como a Sociologia Nacional, a Teoria da Dependência e a Teoria do "Novo Autoritarismo" (Liedke Fo., 2003). 
O texto de Rodolfo Stavenhagen, "Siete tesis equivocadas sobre América Latina: sociología y subdesarrollo", publicado em 1973, no México, foi um marco nesta ruptura crítica com as teorias desenvolvimentistas e modernizantes (Stavenhagen, 1973, in: Durand, 1974).

Alvarado Y Santander afirmam que vários autores, como

...Theotonio Dos Santos, Vania Bambirria, Andre Gunder Frank y Enzo Faletto, entre muchos otros, comienzan a cuestionar la posibilidad del logro del desarrollo socio-económico desde la copia respecto de los procesos vividos por los países centrales «metropolitanos». En lo fundamental, se plantea que el subdesarrollo no se basa en la especificidad cultural, sino en la dinámica histórica de carácter dialéctico que requiere de países que aporten materias primas y mano de obra barata, frente a sociedades centrales que poseen el capital y la tecnología. La especificidad histórica es entendida por los teóricos de la dependencia como el desarrollo histórico de una estructura productiva y social, asumida como un sistema de clases que produce bienes y servicios, y que en este modo de producción mantienen entre sí una relación tensionada (2003).

Esta foi, na obra de Florestan Fernandes, a "etapa da reflexão sobre a revolução burguesa no Brasil (1967-1986)", marcada por seu livro "A Revolução Burguesa no Brasil', seguida de um período posterior (1986-1995)" de "militância cidadã" (Liedke Filho, 2003b).

O livro de Fernando Henrique Cardoso e Enzo Faletto, "Dependência e Desenvolvimento na América Latina", escrito entre 1966 e 1967 no Chile, no âmbito da CEPAL, publicado primeiro no Chile e no México e, em 1970, no Brasil, foi a obra sociológica da região que mais repercussão internacional obteve. O objetivo segundo Cardoso e Faletto consistia em: 
...esclarecer alguns pontos controvertidos sobre as condições, possibilidades e formas do desenvolvimento econômico em países que mantêm relações de dependência com os pólos hegemônicos do sistema capitalista, mas, ao mesmo tempo, constituíram-se como Nações e organizaram Estados Nacionais que, como todo Estado, aspiram à soberania (1973, p. 7).

Os autores propõem, então, o conceito de dependência: "A noção de dependência alude diretamente às condições de existência e funcionamento do sistema econômico e do sistema político, mostrando a vinculação entre ambos, tanto no que se refere ao plano interno dos países como ao externo" (Cardoso e Faletto, 1973, p. 27).

O grande mérito do livro pode ser assim sintetizado:

A discussão comparativa da crise sócio-política das sociedades latino-americanas no período de "expansão para fora", tendo por referência os conceitos de "situações de controle nacional do sistema produtivo" (Argentina, Brasil, Uruguai e Colômbia) versus "situações de economia de enclave" (México, Bolívia, Venezuela, Chile, Peru e América Central), representou uma renovação de interpretação da história latino-americana. Ao mesmo tempo, propunha a necessidade de abranger "o caráter novo da dependência" a internacionalização do mercado - através da abertura dos mercados internos ao controle externo, via ingresso de capitais estrangeiros (Liedke $F^{o} ., 2003 b$ ).

Na América Latina, houve diferenças na relação entre os governos militares e o desenvolvimento acadêmico e da ciência e tecnologia. Brunner e Bairros (1987) argumentam que:

los autoritarismos militares - si bien con diferencias extremas entre los casos de Argentina, Chile y Uruguay 
por un lado, y el caso de Brasil por otro - afectarían la institucionalidad universitaria, considerada en todas partes una pieza estratégica para la formación de las elites, para la reproducción de la cultura superior de la nación, para la movilidad social de las capas mediste, para la distribución del personal profesional y semiprofesional entre los diversos segmentos del mercado ocupacional y para la socialización política de la juventud (Brunner y Barrios, 1987, p. 42).

No caso brasileiro, após os expurgos de professores e pesquisadores de diversas instituições, em 1964 e em 1968, houve a incorporação do desenvolvimento científico e tecnológico ao modelo de desenvolvimento e de geopolítica adotados, principalmente após 1975, etapa da denominada "transição gradual". Na Argentina (1966-1983), Chile (1973-1989) e Uruguai (1973-1985), houve um autoritarismo repressivo e destruidor das instituições universitárias na área das ciências sociais.

\section{Autoritarismo, Democracia e Exclusão Social (1983-2000)}

A partir da Argentina, em 1983, os processos de redemocratização nos diversos países (Brasil, 1985; Chile, 1989), configuram novos processos sociais, predominando na Sociologia o debate sobre autoritarismo, democracia e exclusão social.

Houve, então, a possibilidade de uma dispersão pela América Latina e Caribe dos Congressos da ALAS. Em 1985, realizou-se o XVI Congresso da ALAS no Rio de Janeiro, sob a coordenação de Theotônio dos Santos. Em 1987, foi realizado em Montevidéu o XVII Congresso da ALAS, no qual foi eleito presidente Geronimo de Sierra. Em 1991, houve o único evento da ALAS realizado em Cuba, o XVIII Congresso da ALAS, em Havana, no qual Luis Suárez Salazar foi eleito Presidente. Suárez escreveu, então: 
Es hora de dar una mirada crítica a todo lo que han hecho nuestros pueblos, sus actores políticos, los nuevos y viejos movimientos sociales en aras de impulsar la construcción de una vida más justa y de un espacio de autonomía en el excluyente sistema mundial que hoy nos oprime a todos por igual (...) (1992, p. 13).

Entre os debates esteve a questão do Estado na América Latina, resumida por MARINI em três aspectos:

El primer tiene que ver con los modos de participación de la sociedad en las estructuras y en el ejercicio del poder, es decir, con la democracia. El segundo, con la capacidad de esa sociedad para formular e instrumentar políticas atendiendo a sus propios intereses, lo que atañe a la economía y, por ende, a la dependencia. La tercera cuestión, en fin, se plantea en la perspectiva del futuro de América Latina, en el contexto de las transformaciones por las que pasa el mundo en este fin de siglo (Marini, 1992, p. 177, in: Suárez, 1992).

O mesmo tema foi abordado por Calderón e Dos Santos (In Suárez, 1992, p.185-213), também publicado em livro, com a proposição de vinte teses para uma nova ordem estatal na América Latina, com uma orientação teórica:

En la reestructuración de la economía mundial y en su incidencia sobre la región hay un alto componente sociopolítico y no meramente económico, pues es falsa la derivación mecánica 'crisis - ajuste estructural (...) El nuevo ciclo histórico se caracteriza por la conjugación de un proceso de democratización del régimen político que tiende a ser políticamente incluyente y un proceso de modernización del Estado que tiende a ser socialmente excluyente (Calderón e Dos Santos, 1991, p. 15 e p. 20). 
O Congresso seguinte foi realizado em Caracas, em 1993. Nesta ocasião, o sociólogo Heinz Sonntag foi eleito presidente do XIX Congresso da ALAS (Briceño-Leon e Sontag, 1998) que contou com discussões principais sobre: a viabilidade democrática na América Latina nos anos 90; modelos de desenvolvimento alternativo e políticas sociais; cultura, modernidade e tradição cultural, e democracia, cidadania e representatividade.

Neste período, foi notável a densidade da contribuição teórica e interpretativa dos sociólogos, em distintos países da América Latina: no Peru, José Matos Mar, Aníbal Quijano e Julio Cotler (Clases, Estado y Nacíon en el Perú, 1978). Já mencionamos a produção sociológica no Chile, de Enzo Faletto, José Brunner, Norbert Lechner, Sérgio Gómez e tantos outros.

No Brasil, Florestan Fernandes, Octavio Ianni, Fernando Henrique Cardoso, José da Sousa Martins, Gabriel Cohn e uma nova geração de jovens sociólogos, muitos voltando de doutoramentos feitos na Universidade de São Paulo, na UnB e no IUPERJ, e em Universidades estrangeiras - na França, Inglaterra, Alemanha, Estados Unidos e México, principalmente - durante os anos de 1980 e 1990.

Houve uma alentada produção nos estudos agrários, desde uma perspectiva crítica, no sentido de superar teoricamente o conceito de modernização, interpretar as transformações das classes sociais no espaço agrário, reconhecer a presença política dos camponeses nas sociedades latinoamericanas e avaliar as transformações sociais do espaço agrário (Gomez e Echenique, 1988; León Lopez et alii, 1999). Desde a monumental coletânea coordenada por Pablo González Casanova sobre a "Historia Política de los Campesinos Latinoamericanos" (1984, 1985), os trabalhos de Roger Bartra (1974, 1981 e 1982) sobre os camponeses e o poder político no México, a mesma temática nas obras de José de Souza Martins, no Brasil, até os estudos sócio-históricos de Arturo Warman, Jacques Chonchol e José Bengoa, a presença dos camponeses como forças sociais foi recolocada 
na América Latina. Por outro lado, multiplicaram-se os estudos sobre as possíveis configurações de uma "nova ruralidade", heterogênea e polissêmica (Giarraca, 2001; Gomez, 2002; Pérez, 2001).

As transformações das sociedades contemporâneas impunham novos desafios à Sociologia na América Latina. Desde a crise global que finalizou o curto Século XX, entre 1989 e 1991 (Hobsbawm, 1994), ao início do Século XXI, cuja fase atual poderíamos denominar de processo de mundialização das conflitualidades sociais, marcado pela globalização da economia, pelo avanço do capital especulativo e pela pós-modernidade como forma cultural.

Um dos mais importantes desafios que todas as coletividades sociológicas da América Latina enfrentaram a partir deste período foi o de construir uma identidade própria e independente, como bem expressou Castañeda Sabido ao referir-se à Sociologia de seu país: "A Sociologia mexicana, para desenvolver-se, deve construir uma identidade própria, independente da sociedade e do Estado" (2004, p. 306).

VI) A consolidação institucional e a mundialização da Sociologia da América Latina (desde o ano de 2000)

No processo de mundialização da Sociologia na América Latina, os dilemas sociais assumem novas configurações:

... o debate atual a respeito das alternativas possíveis face às divisões do mundo globalizado: o alheamento defensivo, o auto-isolamento, vis a vis o apelo à violência; o enraizamento na tradição baseada na autoridade e hierarquia no cumprimento de normas préestabelecidas vis a vis o diálogo democrático face a demandas crescentes de participação social em espaços públicos (Liedke, 2003, p. 15). 
Trata-se de um período de progressiva construção da democracia política na América Latina, com processos diferenciados de redemocratização - os acordos de paz nos países da América Central (Nicarágua, Guatemala, El Salvador) e de construção do Estado Democrático de Direito, com crescentes reclamações por direitos humanos, por direitos sociais e direitos coletivos difusos, ou o denominado direito à diferença, com vistas a uma democracia social ampliada e ao exercício constante e pleno da cidadania. Uma época de debate teórico entre as noções de Estado, classes sociais e novos movimentos sociais (Larangeira, 1990; Scherer-Warren \& Krischke, 1987 Medeiros, 1989), pleno de discussões acerca da modernidade, da pós-modernidade ou de um ainda indefinido "neo-socialismo" (Ianni, 1996, 2000; Pierucci, 1999; Domingos, 1999).

Na Sociologia atual, "existe uma preocupação constante com o aumento da exclusão social e uma tentativa de encontrar modelos que possibilitem práticas e ações de inclusão social" (Barreira, 2003, p. 15). Os Congressos de ALAS da década de 1990 expressaram esta preocupação.

Em 1995, foi realizado, no México, o XX Congresso da ALAS, tendo sido eleita presidente Raquel Sosa. O tema do congresso era "América Latina e o Caribe: perspectivas de sua reconstrução" e se realizou, naquele momento, uma revisão crítica da produção sociológica, reafirmou-se a responsabilidade dos sociólogos: "Los latinoamericanos tenemos la fuerza de la historia y de nuestra identidad para contestar la adversidad y proponernos emprender una lucha cierta y de largo alcance por la reconstrucción de nuestros países" (Sosa, 1996, p. 5)

As principais questões sociais e políticas discutidas, escreveu Sosa, foram as seguintes:

Los retos contemporáneos del pensamiento social latinoamericano, la globalización, la integración de América Latina en el nuevo escenario mundial, la 
cuestión de las migraciones y fronteras, la transición demográfica, los problemas de la transición a la democracia, la cultura política y los medios de comunicación, ${ }^{12}$ la violencia política, la crisis agraria y urbana, las perspectivas de recuperación del medio ambiente y la formulación de un programa de desarrollo sustentable, los problemas de género y la autonomía de las etnias (1966, p. 6)

Em outras palavras, três ordens de temas sociológicos estiveram presentes no Congresso da ALAS no México:

1) cuestiones de teoría, metodología, ética, valores y su relación con el conocimiento de la América Latina; 2) revisión de las grandes interpretaciones consagradas sobre la problemática de la región (...); las ciencias sociales ante las nuevas problemáticas, categorías, instituciones y formas de movimiento y participación social, política y cultural en la América Latina (Olivier, 1996, p. 5)

A produção de novos saberes a partir das lutas e movimentos sociais, em uma conjuntura de retomada das críticas à hegemonia neoliberal como o Movimento Zapatista - ocorria, expressava Gonzalez Casanova,

en pequeños zigzagueos, como fractales, reales y utópicos, y se manifiesta con sobreentendidos que contienen fuertes elementos de ambigüedad y de confusión, los cuales sólo se precisan y despejan conforme los movimientos sociales y políticos actúan en las luchas por objetivos inmediatos, y conforme comparten el pensar de sus experiencias prácticas, comparten sus experiencias imaginativas, comparten sus experiencias de luchas cotidianas hasta aceptarlas e 
internalizarlas en un pensar común al movimiento (1996, p. 24, in: Sosa, 1976).

A questão das perspectivas da democracia na América Latina era o grande tema naquele momento, assinalava Dario Salinas:

Constatar que la política ha cambiado seguramente no constituye una mayor novedad. El problema estriba en averiguar si ese cambio es más benéfico para el pueblo, para sus planteamientos de participación en los asuntos fundamentales de la sociedad y la resolución de sus problemas de bienestar (Salinas, 1999, p. 10).

O congresso seguinte, o XXI Congresso da ALAS, foi realizado em 1997, na Universidade de São Paulo, na cidade de São Paulo, elegendo-se presidente Emir Sader. A Declaração final do XXI Congresso estabelece uma clara análise da América Latina no limiar do Século XXI:

Hoje existem na maioria de nossos países regimes de democracia representativa. Neles se manifesta uma luta entre concepções, projetos, forças e tendências orientadas em sentidos diversos. Por uma parte, coloca-se uma opção que favorece a crescente concentração do poder econômico e político, a exclusão majoritária e a prática de programas para reforçar o controle social, assegurar a governabilidade e limitar a participação popular na vida pública. Por outra, a democracia serviu para ampliar a presença das coletividades, a formação de redes horizontais das organizações culturais, políticas e dos movimentos sociais; para estimular e aprofundar a mudança nas formas e meios mesmo da atividade pública, o estabelecimento de novas relações e vias de comunicação alternativa, o estabelecimento dos princípios de uma institucionalidade participativa e de uma cultura democrática. (...). A riqueza de experiências e propostas democráticas surgidas 
nos últimos anos é notória. A Associação Latinoamericana de Sociologia ratifica seu compromisso com o impulso de um pensamento latino-americano próprio, não colonial, identificado com os problemas e as lutas das maiorias, com o objetivo de alcançar uma democracia de todos e para todos, sem exclusões nem excluídos da mesma.

O livro publicado por Emir Sader reafirmava que "las sociedades latinoamericanas viven una de las más grandes crisis sociales de su historia", lo que "requiere del pensamiento social no solamente diagnósticos sobre las ráices de esa crisis, sino también responsabilidad política para proponer y contribuir para que triunfen alternativas a las políticas neoliberales" (Sader, 1998). Octavio lanni publicou, neste livro, um artigo que resumia sua contribuição à explicação sociológica da "era do globalismo":

El globalismo se revela como una totalidad no sólo geohistórica sino también social, económica, política y cultural comprehensiva. Se trata de una totalidad compleja. Heterogénea, desigual, contradictoria, integrada y fragmentaria, en la que se ubican y se mueven individuos y colectividades, grupos y clases, tribus y naciones (lanni, in: Sader, 1998, p. 17). ${ }^{13}$

Vivíamos um apregoado neoliberalismo, produtor de um processo de globalização econômica, de um pensamento "único" e de crescentes desigualdades sociais, um "mundo de miséria" em "tiempos violentos" (Boron e Gambina \& Minsburg, 1999). Também a experiência cubana enfrentava os desafios provocados pelas transformações de sua inserção na economia mundial (Cips, 2003; Suárez, 2001). Em 1999, foi organizado o XXII Congresso da ALAS, em Concepción, no Chile, quando Eduardo Aquevedo Soto foi eleito presidente. A partir do tema "Para onde vai a América Latina", a declaração final do Congresso afirmava: 
La alternativa, desde nuestro punto de vista, debe fundarse en el fortalecimiento de las democracias a nivel nacional, de las alianzas y de la solidaridad entre todos los países del continente y los de la periferia del planeta, excluidos de los mega-mercados de los países ricos. En primer lugar, advierten que, en medio de la crisis de los modelos neoliberales, es necesario construir alternativas de desarrollo sostenido, que articulen productividad y equidad social. Ello sólo será posible mediante la extensión del mercado interno y políticas eficaces de redistribución de la riqueza.

Además, los sociólogos reunidos aceptamos el recto de aportar a promover una nueva visión de la región basada en el desarrollo de una infraestructura científica y tecnológica apropiada a los requerimientos de nuestras sociedades. Creemos que es posible en efecto aportar con nuestros trabajos a liberar las energías sociales contenidas en los movimientos de jóvenes, mujeres y pueblos indígenas, por la defensa de sus derechos la libertad, la justicia, la diversidad cultural, la soberanía y la sustentabilidad ecológica, entre otros.

Expressando a mundialização da Sociologia na América Latina, foi realizada, em 2001, a Primeira Conferência Regional da ISA - Associação Internacional de Sociologia - na Venezuela, coordenada por Roberto Briceño-León e pela Associação Venezuelana de Sociologia. Briceño-León empreende, então, a seguinte análise sobre a Sociologia:

Tres características nos parecen que ha que detener esa Sociología en este siglo que se inicia: la de ser empírica, ecléctica y comprometida. (...). La respuesta ecléctica que ha de dar la sociología desde América Latina tiene su fundamento en el propio mestizaje del continente, como realidad a la cual hay que explicar en su singularidad, y como postura política de incorporación de los excluidos (Briceño-León, 2001, 


$$
\text { p. } 54 \text { y p. 61, in Romero Salazar, 2001). }
$$

A preocupação com a responsabilidade social da Sociologia da América Latina já se manifestava em texto anterior do Autor:

Debemos dar cuenta del pueblo, de la singularidad de nuestras sociedades, no debe perderse para nada la vocación empática del dolerse del dolor del otro, (...), ni tampoco debe abandonarse la idea del cambio social y de la contribución que tiene que hacer la Sociología para transformar las sociedades injustas y subdesarrolladas en las cuales vivimos. Pero también debemos dar cuenta de la época con todas las herramientas científicas posibles (...) (Sonntag \& Briceño-León, 1998, p. 24).

Aceitando a análise desenvolvida por Hobsbawm em relação ao final do século XX, a Era dos Extremos, podemos definir o século XXI, em seu primeiro período, em curso desde 1991, como o período do processo de mundialização caracterizado pela globalização das atividades capitalistas, pela crise global e pelas culturas híbridas na América Latina (Garcia Canclini, 1989; Strasser, 2000; Ianni, 2000; Calderón \& Santos, 1995).

Foram dez anos nos quais se chegou a uma mundialização de análises, discussões e debates sobre algumas das novas questões sociais globais, principalmente através de conferências promovidas por organismos internacionais como a ONU: a Declaração dos Direitos da Criança, em 1989; a ECO-92, discutindo a questão da relação entre os homens e o ambiente, no Brasil, em 1992; a Conferência sobre População e Desenvolvimento, no Egito, em 1994; a IV Conferência Mundial sobre a Mulher, realizada em Beijing, na China, em 1995; A Cimeira Mundial para o Desenvolvimento Social, em Copenhague, no ano de 1995 e a Conferência HABITAT II, em Istambul, sobre a questão da moradia, no ano de 1996, e a Confe- 
rência Mundial sobre a Alimentação, em Roma, em 1996.

Em meados dos anos 90, inicia-se uma nova vaga de protestos contra os efeitos do processo de globalização, um processo de constituição de formas sociais marcadas pelos efeitos excludentes das políticas neoliberais, desencadeando novos conflitos sociais e, por vezes, estabelecendo limites à consolidação da democracia nos países periféricos do mundo capitalista: do movimento zapatista, em janeiro de 1994, às manifestações contra as reuniões dos organismos financeiros internacionais. Em outras palavras, escreve Theotonio dos Santos:

Procuramos demonstrar (...) como a doutrina neoliberal se impôs no mundo contemporâneo e como as políticas econômicas delas derivadas produziram terríveis desequilíbrios na economia mundial conduzindo-nos ao mal-estar generalizado a que a sociedade contemporânea nos fez submergir (Santos, 2004).

Contra tal mal-estar da civilização contemporânea, desenvolve-se um processo mundial de debates acerca de "um outro mundo possível", o que vem acontecendo desde o 1 o Fórum Social Mundial de Porto Alegre, em 2001, até o 5o FSM, na mesma cidade, no ano de 2005:

El nuevo siglo empezó efectivamente en Porto Alegre = otro mundo es posible. Un mundo en el que se suprimiría la deuda externa; en el que los países pobres del Sur jugarían un papel más importante; en el que se pondría fin a los ajustes estructurales; en el que aplicaría la tasa Tobin en los mercados de divisas; en el que suprimirían los paraísos fiscales; en el que se aumentaría la ayuda al desarrollo y en el que éste no adoptaría el modelo del Norte, ecologicamente insostenible; en el que se invertiría masivamente en escuelas, alojamiento y sanidad; en el que se favorecería el acceso al agua potable de la que carecen 1.400 millones de personas; en el que se obraría seriamente 
por la emancipación de la mujer; en el que se aplicaría el principio de precaución contra todas las manipulaciones genéticas y en el que se frenaría la actual privatización de la vida (Ramonet, 2001; Seoane \& Taddei, 2001; Cattani, 2001).

As questões sociais, desde o século XIX centradas em torno do trabaIho (Castel, 1998), tornam-se questões complexas e globais, pois várias são as dimensões do social que passam a ser socialmente questionadas, entre elas a questão dos laços sociais. As transformações do mundo do trabalho, mediante as mudanças tecnológicas que vêm acompanhadas pela precarização do trabalho, pela crise dos sindicatos, pelo desemprego e pelo processo de seleção/exclusão social. (Larangeira, in: Tavares Dos Santos, 1999; Sierra, 2001; Sobral Fonseca e Porto Grossi, 2001; Cardoso, 2003). ${ }^{14}$

Entre os conflitos sociais atuais, crescem os fenômenos da violência difusa. Os fenômenos da violência adquirem novos contornos, passando a disseminar-se por toda a sociedade (Pinheiro, 1982, 1983 e 1998; Preciado, 2004; Revista Delito y Sociedad, 1992-2004). Esta multiplicidade das formas de violência presentes nas sociedades contemporâneas - violência ecológica, exclusão social, violência entre os gêneros, racismos, violência na escola - configura-se como um processo de dilaceramento da cidadania (Tavares-Dos-Santos, 1999; Briceño-León, 2002; Sosa, 2004). Expande-se, pelo planeta, a opção pelo crescimento das funções de controle social repressivo da policia, com o apelo sistemático ao uso da violência ilegal e ilegítima, configurando um "estado de controle social penal". ${ }^{15} \mathrm{Em}$ outras palavras, estamos diante de formas contemporâneas de controle social, com as características de um Estado repressivo acompanhando a crise do Estado-Providência: "Lo que está en cuestión es como y por qué las democracias conocidas cargan con alguna parte de la culpa por el tremendo cuadro de desigualdades y crecimiento de la desiguldad que hoy 
Há uma visibilidade e uma conceituação da importância das lutas sociais contra a mundialização da injustiça: encontramos novos agentes da resistência, estamos diante da negação da centralidade do poder estatal no espaço-tempo social, afirmando uma outra cartografia, pontilhista e processual, na ordenação do mundo social. No quadro da crise das cidades latinoamericanas seria, então, possível, pensar a construção de uma cidadania transnacional ou mundial, marcada pela criação de práticas sociais, jurídicas e simbólicas inovadoras e globais (Ribeiro Torres, 2004; Joseph, 2005).

Desencadeiam-se processos de exclusão social - os sem-classe, sem terra, sem informática, sem teto, sem comida, sem trabalho - por vezes atingindo mais a juventude (Balardini, 2000; Tavares-Dos-Santos, 2002). Um novo espaço social mundial de conflitualidades se está desenhando nos espaços e nos tempos da "era do globalismo" (Ianni, 1996; Mazzei, 2002; Minujin, 1995; Beccaria \& López, 1996; Souza Martins, 2002). Contra a sociedade normalizadora e programada, efeito de uma tecnologia de poder centrada na vida, e de um Estado orientado para o controle social penal, emergem, no jovem século XXI, forças sociais de resistência, desde as "protestas" até os movimentos sociais, buscando alternativas ao "imperialismo" (Giarracca, 2001; Borón, 2002; Almeyra, 2004; Cels, 2003; Seoane, 2003; Scribano, 2003).

No ano de 2001, ocorreu o XXIII Congresso da ALAS, na cidade de Antigua, Guatemala. Nesta ocasião Eduardo Velásquez foi eleito presidente. Assim se expressaram os participantes deste evento em seu documento final:

Los científicos sociales reunidos por ALAS en Antigua reiteramos nuestro compromiso con un pensamiento critico y humanista, comprometido con la justicia y con la paz; en lucha contra las diversas formas de opresión que aplastan hoy a nuestros pueblos; en una 
persistente búsqueda para consolidar la identidad, recobrar la integridad y dignidad; engañar la integración económica, social y cultural de nuestros pueblos y participar activamente en la construcción de un mundo mejor y en paz.

O XXIV Congresso da ALAS teve lugar em Arequipa, no Peru, no ano de 2003, e Jordan Rosas Valdivia foi o presidente eleito (Zeballos, Salinas e Tavares-Dos-Santos, 2005). O tema central expressou o momento que vive nosso Continente: "Sociedade Civil: atores e organizações". Afirmava a declaração final:

Los científicos sociales de esta región del mundo, comprometidos permanentemente con su acontecer, podemos aportar con vocación, creatividad e iniciativa en el presente y el próximo período a que estas nuevas posibilidades de desarrollo cristalicen y si consoliden en beneficio de la sociedad. En esta oportunidad, nuestro rol crítico cobra una vez más toda su fuerza y vigencia.

Muito se discutiu, em Arequipa, sobre a desigualdade, a pobreza e a exclusão nas sociedades latino-americanas, em suas várias dimensões: precarização do trabalho, pobreza urbana, os novos pobres e a ruptura dos laços sociais. Por outro lado, começam a acontecer experiências, duras, sofridas, porém alvissareiras, de reconstrução das sociabilidades, das lutas sociais aos movimentos sociais, do protesto à participação política. Percebemos, então, que os excluídos estão, na realidade, incluindo-se em um novo passo da História. Vislumbram-se alternativas: a reconstituição de formas de geração de renda, a configuração do capital social, mediante redes de solidariedade; e, sob um leito de vulnerabilidade, os processos pelos quais emergem ações coletivas capazes de forjar esperanças para os excluídos pelo modelo hegemônico de globalização (Díaz \& Cattani, 2004). 
Uma vez mais, o conhecimento crítico enfrentava os desafios de interpretar as transformações sociais mundiais e seus efeitos sociais e epistemológicos sobre a Sociologia na América Latina (Lande, 2003; Sanchez e Sosa, 2004; Delich, 2004; Barreira, 2003). Nessa perspectiva, podemos encontrar uma síntese das principais contribuições ou reinterpretações das ciências sociais da América Latina ao conhecimento sociológico, na segunda metade do Século XX, nos conceitos evocados por Pablo Gonzalez Casanova:

1) Independencia política. 2) Orden. 3) Progreso (y desarrollo). 4) Libertad. 5) Revolución. 6) Marginación. 7) Centro-periferia (y relación de intercambio). 8) Dependencia (con búsqueda de la independencia económica, social, política y cultural, o con un nacionalismo superado y el reconocimiento de un capitalismo global. 9) Colonialismo interno. 10) Revolución socialista y revolución moral. 11) Sistemas políticos y sistemas de poder. 12) Sociedad informal y formalismo autoritario, y el de sociedad informal neoliberal. 13) Explotación. 14) Pedagogía del oprimido y pedagogía colectiva (con lectura de textos y del mundo). 15) Teología de la liberación (respeto a la fé y opción por los pobres. 16) Democracia. 17) Postmodernismo radical y construcción del mundo (con luchas y negociación; con autonomías y redes). Se centra en el concepto de "Democracia de todos" e incluye las etnias y la sociedad civil (González Casanova, 1999, p. 7).

\section{Perspectivas da Sociologia Contemporânea na América Latina}


O tema do XXV Congresso da ALAS - Associação Latino-americana de Sociologia realizado em Porto Alegre em agosto de 2005 tem como tema: "Desenvolvimento, crise e democracia: participação, movimentos sociais e teoria sociológica". Os eixos centrais são: 1) os dilemas e as possibilidades da democracia na América Latina, Centro-América e no Caribe: entre a violência política e a ética; e 2) os desafios teóricos, clássicos e contemporâneos, da Sociologia na América Latina.

Tais problemas sociais e sociológicos devem ser analisados e discutidos em cerca de sete conferências, 22 mesas-redondas, seis fóruns e encontros e 29 grupos de trabalhos, nos quais estão inscritas mais de 1000 comunicações.

Podemos sintetizar as questões sociais e os problemas sociológicos em uma agenda emergente para a Sociologia na América Latina:

O desenvolvimento da Sociologia: conceitos, metodologias, instituições de ensino e pesquisa e associações e sindicatos;

Desenvolvimento e crise da sociedade: espaços rurais, migrações, cidades, meio ambiente e estruturas sociais;

Mundialização, conhecimentos, redes, relações internacionais, sustentabilidade e alternativas democráticas mundiais;

Processos e crise das instituições de socialização: família, escola e os dilemas da infância e da juventude;

Reestruturação produtiva, precarização do trabalho, vulnerabilidade e exclusão social;

Sociologia das diferenças: as relações de gênero, as relações étnicas e a diversidade cultural;

Estado e políticas sociais: neoliberalismo, governabilidade, concertação e gestão social;

Controle social, violência, administração da justiça e direitos humanos;

Movimentos sociais, sociedade civil e protestos sociais;

Culturas híbridas, cultura política, meios de comunicação, consumos e práticas culturais, as religiões e o imaginário. 
A convocatória do XXV ALAS expressa as preocupações atuais dos sociólogos na América Latina:

Os Congressos da ALAS realizados na última década em São Paulo, Concepción, Guatemala Antigua e Arequipa - examinaram as distintas fases do desenvolvimento dos modelos e processos de reestruturação de nossas sociedades, iniciado nas décadas precedentes, com a chamada era de globalização e auge do capitalismo neoliberal. Assistimos, por conseqüência, à precarização do trabalho, à pobreza generalizada e à exclusão social, à deterioração do meio ambiente e a crise dos processos democratizantes nos países latinoamericanos. Por outro lado, o papel da sociedade civil - dos movimentos de camponeses, trabalhadores sem terra, cidadãos e das entidades da sociedade civil, bem como das ONGs - adquiriu uma real importância na crítica social e na proposição de alternativas de desenvolvimento econômico e social. Neste contexto, as manifestações de protesto, resistência social, política e cultural dos atores sociais têm um papel fundamental. Os movimentos sociais cresceram e as formas de participação social nos países da América Latina se multiplicaram, constituindo-se em um agente central nos processos de defesa e de construção democrática. As novas perspectivas que se abrem neste começo de século para os povos latino-americanos nos levam a pensar mudanças políticas, sociais, econômicas e inclusive culturais no continente. Mudanças com perspectivas de sustentabilidade, eqüidade e justiça social, a fim de garantir um futuro melhor para os povos latinoamericanos (www.ufrgs.br/alaspoa). 


\section{Conclusão: a Sociologia e a sociedade na América Latina}

A Sociologia, neste jovem Século XXI, expressa as profundas transformações das sociedades contemporâneas. Configuram-se novas formas do social, novos agentes, outras lutas sociais, emergindo processos sociais inovadores e representações sociais diferenciadas (Tavares-Dos-Santos, 2003, p. 195, in: Barreira, 2003).

O primeiro período do Século XXI é marcado pela globalização dos processos econômicos e pela mundialização das novas questões sociais. Pode-se entender a globalização, segundo Therborn, como "estando relacionada a tendências de alcance, impacto ou encadeamentos globais dos fenômenos sociais, ou a uma consciência de abrangência mundial entre os atores sociais" (Therborn, 2001, p. 125). A posição social das populações mais diretamente atingidas pela globalização caracteriza-se pela desigualdade de oportunidades de vida, isto é, um acesso desigual a recursos e uma vivência de situações sociais desiguais, as quais podem ser resumidas em oito dimensões: saúde, habitação, trabalho, educação, relações de sociabilidade, segurança, informação e conhecimento, e participação política. Poderíamos reconhecer em cada uma dessas dimensões, em função da conscientização dos agentes sociais e de suas distintas posições de classe, de gênero e de étnica, a configuração de novas questões sociais mundiais.

O período atual do processo de mundialização é marcado pela pósmodernidade como forma cultural, pela utilização intensiva do conhecimento científico, que passou a constituir-se em elemento decisivo no processo de construção da sociedade capitalista, pela expansão da produção industrial, pelo avanço do capital especulativo e pela crise social mundial. Ainda mais, "uma revolução tecnológica concentrada nas tecnologias da informação está remodelando a base material da sociedade em ritmo acelerado" (Castells, 2000, p. 21). 
Nos últimos vinte anos do velho século, ciência e tecnologia que, em estreita vinculação, já desempenhavam papel estratégico como força produtiva, dão lugar à tecnociência - um sistema de ações eficientes, baseadas em conhecimento científico. Essas ações se orientam tanto para a natureza quanto para a sociedade, visando transformar o mundo, para além de descrever, predizer, explicar, compreender. A tecnociência implica a empresarialização da atividade científica e, sendo um fator relevante de inovação e de desenvolvimento econômico, passa a ser também um poder dominante na sociedade, tendendo sua prática ao segredo e à privatização (Echeverría, 2003).

Ciência, tecnologia e inovação afirmam-se, cada vez mais, como o motor da grande competição que leva à supremacia econômica, ao progresso, ao desenvolvimento econômico e social. A definição de suas finalidades atende, neste contexto, diretamente ao mercado (Baumgarten, 2005).

O papel estratégico desempenhado pela ciência e pela tecnologia no contexto contemporâneo e a desigual difusão das capacitações para produzir e utilizar a ciência entre as diferentes nações recolocam, de forma ampliada, as dificuldades de inserção na economia mundial daqueles países periféricos e dependentes de conhecimento e inovação gerados nos centros dinâmicos da economia capitalista (Hassam, 1999).

A análise da relação entre desenvolvimento econômico capitalista e sustentabilidade social e natural, no terço final do século XX, indica enormes contradições, tanto em termos de diferenças entre o discurso e a prática do Estado, quanto relativamente à própria ação dos vários atores sociais envolvidos. Os rumos do desenvolvimento capitalista no mundo e, também, na América Latina não parecem estar-se orientando no sentido de uma nova consciência planetária e de ações visando a sustentabilidade, e sim, ao contrário, para a resolução dos problemas imediatos de ajuste da 
economia e interesses das nações hegemônicas (Fiori, 2003; Dupas, 2000; Bursztyn, 2001; Baumgarten, 2002).

Ao mesmo tempo, o impacto crescente da globalização e as características lucrativas das dinâmicas da tecnociência se traduzem em uma maior relevância no desenvolvimento da internacionalização das instituições educativas e de pesquisa (Guadilla, 2004). O exponencial aumento na intensidade das interações entre as coletividades científicas internacionais, facilitado pelas novas tecnologias eletrônicas e de comunicação, tem levado à formação de redes em torno das atividades de C\&T. Tais redes ultrapassam os contextos institucionais de origem (universidades, institutos de pesquisa, empresas, governos) obtendo crescente autonomia (Castells, 2000).

No contexto do novo século, cresceu a importância da cooperação transnacional entre instituições de ensino e pesquisa e instituições corporativas, tornando-se norma nos centros desenvolvidos. Em contraste, a colaboração internacional é entorpecida nos países do sul em decorrência da baixa participação da indústria no financiamento da pesquisa e de sua preferência em importar pacotes tecnológicos prontos, o que aumenta o grau de dependência científico-tecnológico desses países (Braun, 1999).

Neste panorama mundial atual, marcado por questões sociais globais, que se manifestam, de forma articulada, mas com distintas especificidades, nas diferentes sociedades, a Sociologia, na América Latina, tem contribuído para o debate sobre as mudanças que acompanham as novas formas de produção da vida material, imaterial e do conhecimento na sociedade.

As transformações sociais e as urgências da vida coletiva fazem com que os grupos sociais peçam os saberes sociológicos para explicar os processos sociais e históricos. Crescem as demandas públicas, por agências 
estatais, das empresas privadas e das associações e sindicatos, pela investigação, como efeito das grandes perturbações cognitivas e identitárias provocadas pelas transformações sociais de nossa época.

A qualidade do trabalho científico do sociólogo se compõe por um imperativo de responsabilidade social, de respeito aos direitos humanos e de conduta acadêmica orientada pela justiça que o tornam um cientista social habilitado a respeitar tanto o mérito científico assim como, a relevância social de sua pesquisa.

As novas questões sociais mundiais constituem um vasto campo de interrogações à prática sociológica. Estão relacionadas, por um lado, à intensificação das relações de produção e de mudança mercantil no espaço planetário, à globalização da economia e à reestruturação do capital e do trabalho. Por outro lado, expressam a redução da capacidade regulatória dos Estados Nacionais sobre o ordenamento do trabalho e da produção de mercadorias em seus territórios: crise de hegemonia, violência política e social, violações de direitos humanos (Marini \& Millán, 1996). Se muitas são as possibilidades emancipadoras, há um universo de exclusão social e de segregação sócioespacial - por classes, gêneros, etnias, afinidades culturais, grupos de idade - que exige uma teoria crítica da sociedade contemporânea.

A Sociologia latino-americana está inserida no espaço mundializado do conhecimento sociológico: conquistou plena legitimidade acadêmica e científica, sendo reconhecida pela sociedade civil e pelo Estado como saber construtor de uma consciência crítica da realidade social.

Os elementos do pensamento sociológico - investigação científica, compromisso político e imaginação sociológica - foram-se construindo em uma tensa e estimulante inserção, unindo o rigor da pesquisa e o pensamento crítico aos processos de transformação social da América Latina, acompanhando as rupturas epistemológicas do tempo presente: 
... el pensamiento crítico tiene mayores posibilidades de triunfo si redefine la dialéctica con las tecnociencias y con las ciencias de la complejidad, siempre que fortalezca el pensar-hacer de las relaciones contradictorias con las experiencias críticas de las clases, las naciones, las ciudadanías, y que las organice como complejos y redes para alcanzar objetivos (González Casanova, 2004, p. 438)

Nesta aventura sociológica - por tempos sociais do passado ao futuro, percorrendo espaços sociais em interações entre o local, o nacional e o planetário - um acontecimento conclama os sociólogos da América Latina: participar do XXV Congresso Latino-americano de Sociologia, na cidade de Porto Alegre, Brasil, em agosto de 2005.

Reconstruir algumas contribuições dos sociólogos da América Latina à interpretação sociológica, no último século - as quais demonstraram razão crítica e capacidade de análise social - talvez possa sugerir às novas gerações a importância da persistência de um ofício: a Sociologia como saber que adquire o poder simbólico de descrever o fato social, desvelar o mundo e explicar a História, e, com audácia, contribuir para a transformação das solidariedades e utopias latino-americanas no Século XXI. 
Anexo

CONGRESOS Y PRESIDENTES DE ALAS

Fundación de ALAS en el 1er. Congreso de la ISA - Internacional Sociological Association, en Zurich, Suiza

1. 1951 - I - BUENOS AIRES - Alfredo Poviña

2. 1953 - II - RIO DE JANEIRO - Manuel Diegues Junior

3. 1955 - III - QUITO - Alfredo Poviña

4. 1957 - IV - SANTIAGO DE CHILE - Astolfo Tapia

5. 1959 - V - MONTEVIDEO - Isaac Ganon

6. 1961 - VI - CARACAS - Rafael Caldera

7. 1964 - VII - BOGOTÁ - Aníbal Quijano (Vice-Presidente).

8. 1967 - VIII - SAN SALVADOR - Manuel Diegues Junior

9. 1969 - IX - MEXICO - Pablo González Casanova

10. 1972 - X - SANTIAGO DE CHILE - Guillermo Briones

11. 1974 - XI - SAN JOSÉ, COSTA RICA - Daniel Camacho

12. 1977 - XI - QUITO - Agustín Cueva

13. 1979 - XII - CIUDAD DE PANAMÁ - Marco A. Gandásegui

14. 1981 - XIII - SAN JUAN, Puerto Rico - Denis Maldonado

15. 1983 - XV - MANÁGUA - Pablo Gonzales Casanova

16. 1985 - XVI - RIO DE JANEIRO - Teotônio dos Santos

17. 1987-XVII - MONTEVIDEO - Geronimo de Sierra

18. 1991 - XVIII - LA HABANA - Luis Suárez Salazar

19. 1993 - XIX CARACAS - Heinz Sonntag 
20. 1995 - XX - MEXICO - Raquel Sosa Elizaga

21. 1997 - XXI - SÃO PAULO - Emir Sader

22. 1999 - XXII - CONCEPCIÓN - Eduardo Aquevedo Soto

23. 2001 - XXIII - GUATEMALA - Eduardo Vélasquez

24. 2003 - XXIV - AREQUIPA - Jordan Rosas Valdivia

25. 2005 - XXV - PORTO ALEGRE

\section{Bibliografia}

ACEVEDO LÓPEZ, María Guadalupe. Reestructuración Econômica y desarrollo en América Latina. México, Siglo Veintiuno, 2004.

ADORNO, Sérgio et alii. A Sociologia entre a Modernidade e a Contemporaneidade. Porto Alegre: Editora da Universidade - UFRGS, 1995.

ADORNO, Sérgio et alii. Natureza, História e Cultura: Repensando o Social. Porto Alegre: Editora da Universidade - UFRGS, 1993 (Cadernos de Sociologia, v. 4, número especial).

AGUIAR, Flávio (org.). Antonio Candido: pensamento e militância. São Paulo: Humanitas, FFLCH - USP / Ed. Fundação Perseu Abramo, 1999.

ALMEYRA, Guillermo. La protesta social en Argentina (1990-2004). Buenos Aires: Ed. Continente, 2004.

ALVARADO, Miguel and SANTANDER, Pedro. "Matar al padre": Análisis discursivo de dos textos de la sociología chilena en período de dictadura. Lit. lingüíst., n.14, p.135-157. 2003. Disponível em: <http://www.scielo.cl/>

ARAUjO, Heloisa Villena de (org.). Os Países da Comunidade Andina. Brasília: Fundação Alexandre de Gusmão, Instituto de Pesquisa de Relações Internacionais, V. 1 e 2, 2004.

ARRUDA, Maria Arminda do Nascimento \& GARCIA, Sylvia Gemignani. Florestan Fernandes, mestre da Sociologia Moderna. Brasília: CAPES / Paralelo 15, 2003. 
ASOCIACIÓN VENEZOLANA DE SOCIOLOGÍA. Vı Congreso Latinoamericano de Sociología: Memórias. Caracas, Imprenta Nacional, tomo I, 1961.

BAGU, Sergio. Economía de la sociedad colonial (ensayo de historia comparada de América Latina. México: Grijalbo, 1992 (Edición ampliada y actualizada).

BALARDINI, Sergio (comp.). La Participación social y política de los jóvenes em el horizonte del nuevo Siglo. Buenos Aires: CLACSO, 2000.

BARREIRA, César (org.). A Sociologia no Tempo: memória, imaginação e utopia. São Paulo: Cortez, 2003.

BARREIRA, César. Sociologia no Brasil - uma reflexão. Fortaleza, mimeografado, 2003.

BARTRA, Roger. Campesinado y poder político em México. México: ERA, 1982.

BARTRA, Roger. Estructura agrária y clases sociales em México. ERA / UNAM, 1974.

BARTRA, Roger. Las redes imaginarias del poder político. ERA, 1981.

BASTOS RUGAI, Elide. Gilberto Freyre e o pensamento hispânico. Bauru, SP: ANPOCS / EDUSC, 2003.

BAUMGARTEN, M. Conhecimento, planificação e sustentabilidade. In: São Paulo em Perspectiva, São Paulo, Fundação SEADE, v. 16, n. 3, p. 31-41, jul./set. 2002.

BAUMGARTEN, Maíra. A Era do Conhecimento: Mátrix ou Agora ? Porto Alegre: Editora da Universidade - UFRGS; Brasília: Ed. UnB, 2001.

BAUMGARTEN, Maíra. Conhecimentos e Inovação Social: redes e integração regional. In: BAUMGARTEN, M. Conhecimentos e Redes: sociedade, política e inovação. Porto Alegre: Ed. da UFRGS, 2005.

BECCARIA, Luis \& LÓPEZ, Néstor (comp.). Sin trabajo: las características del desempleo y sus efectos en la sociedad argentina. Buenos Aires: UNICEF / Losada, 1996.

BELLOTTO, Mantel L. \& CORRÊA, Anna Maria M. (orgs.). José Carlos Mariátegui: política. São Paulo: Ática, 1982. 
BENGOA, Jose. El Poder y la subordinación. Santiago de Chile: SUR, 1988 (Historia Social de la Agricultura Chilena, Tomo I).

BENGOA, Jose. Haciendas y Campesinos. Santiago de Chile: SUR, 1988 (Historia Social de la Agricultura Chilena, Tomo II).

BOBES LEÓN, Velia Cecilia. Sociología en América Latina. La Habana: Editorial de Ciencias Sociales, 1990.

BOMENY, Helena \& BIRMAN, Patrícia (org.). As assim chamadas Ciências Sociais: formação do cientista social no Brasil. Rio de Janeiro: UERJ / Relume Dumará, 1991.

BORON, Atílio \& GAMBINA, Julio \& MINSBURG, Naum (comp.). Tiempos Violentos. Buenos Aires: CLACSO / Eudeba, 1999.

BORON, Atílio Alberto. Império \& Imperialismo. Buenos Aires: Clacso, 2002.

BOSI, Alfredo. Dialética da Colonização. São Paulo: Companhia das Letras, 1994.

BRAUN, T. et al. As grandes tendências da ciência mundial. UNESCO. In: El Correo, maio de 1999.

BRICEÑO-LEÓN, Roberto (ed.). Violencia, sociedad y justicia en América Latina. Buenos Aires: CLACSO, 2002.

BRUNNER, J. \& BARRIOS, A. Inquisición, Mercado y Filantropía. Ciencias Sociales y Autoritarismo en Argentina, Brasil, Chile y Uruguay. Santiago de Chile: FLACSO, 1987.

BRUNNER, José Joaquín. El caso de la Sociologia en Chile. Santiago de Chile: FLACSO, 1988.

BUARQUE DE HOLANDA, Sérgio. Raízes do Brasil. Rio de Janeiro: José Olympio,

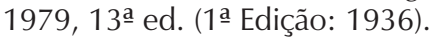

BUARQUE DE HOLANDA, Sérgio. Visão do Paraíso. São Paulo: Nacional, 1977,

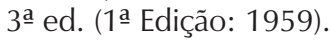

BURSZTYN, M. (org.). Ciência, ética e sustentabilidade. São Paulo: Cortes; Brasília: DF:UNESCO, 2001, p. 159-188.

CALDERÓN, Fernando \& DOS SANTOS, Mario R. Hacia un nuevo orden estatal en América Latina. Chile: FCE / CLACSO, 1991. 
CALDERÓN, Fernando \& DOS SANTOS, Mario R. Sociedad sin Atajos: cultura, política y reestructuración económica en América Latina. Buenos Aires: Paidós, 1995.

CAMACHO, Daniel. Debates sobre a teoria de la dependencia y la Sociologia latinoamericana. São José:EDUCA - Editorial Universitaria Centro-americana, 1979 (Ponencias del XI Congreso Latinoamericano de Sociologia).

CAMARGO, Candido P. F. de et alii. S. P. 1975: crescimento e pobreza. S. P: Loyola, 1976.

CANCLINI, Nestor. Culturas híbridas. México: Grijalbo, 1989.

CANDIDO, Antonio. Florestan Fernandes. São Paulo: Fundação Perseu Abramo, 2001.

CÂNDIDO, Antônio. Os parceiros do Rio Bonito; estudo sobre o caipira paulista e a transformação de seus meios de vida. 3.ed. São Paulo: Livraria Duas Cidades, 1975. (1a edição: 1964, Ed. José Olympio).

CARDOSO, Adalberto M. A Década Neoliberal e a crise dos sindicatos no Brasil. São Paulo: Boitempo Ed., 2003.

CARDOSO, Fernando Henrique \& FALETTO, Enzo. Dependência e desenvolvimento na América Latina. R. J.: Zahar, 1970.

CARDOSO, Fernando Henrique. Mudanças Sociais na América Latina. São Paulo: DIFEL, 1969.

CARVALHO FRANCO, Maria Sylvia. Homens livres na ordem escravocrata. S. P.: Instituto de Estudos Brasileiros - USP, 1969.

CASTAÑEDA SABINO. La crisis de la Sociologia académica en México. México: UNAM, 2004.

CASTEL, Robert. As metamorfoses da questão social. Petrópolis: Vozes, 1998.

CASTELLS, Manuel. La Era de la información: economía, sociedad y cultura. Madrid: Alianza, v. I, 1996 (A sociedade em rede. São Paulo: Paz e Terra, 2000).

CATTANI, Antonio David. Fórum Social Mundial: a construção de um mundo melhor. Petrópolis, Vozes, 2001. 
CELS - Centro de Estúdios Legales y Sociales. El Estado frente a la protesta social (1996-2002). Buenos Aires: Siglo XXI, 2003.

CIPS - Centro de Investigaciones Psicológicas y Sociológicas. La Sociedad Cubana Retos y Transformaciones. Cuba: CIPS, 2003.

COHN, Gabriel. Sociologia da Comunicação: teoria e ideologia. São Paulo: Pioneira, 1973.

COSTA PINTO, L.A. \& CARNEIRO, E. As Ciências Sociais no Brasil. Rio de Janeiro: CAPES, 1955.

COSTA PINTO, Luiz de Aguiar de. Sociologia e desenvolvimento: temas e problemas de nosso tempo. Rio de Janeiro: Civilização Brasileira, 2a․ ed. 1970.

CROVI DRUETTA, Delia (coord.). Cultura política: Informacíon y comunicacíon de masas. México: ALAS, 1996.

CRUZ COSTA. Contribuição à História das Idéias no Brasil. Rio de Janeiro: Civilização Brasileira, 1967, 2aㅡ ed.

CHACON, V. História das Idéias Sociológicas no Brasil. São Paulo: EDUSP, 1977. CHONCHOL, Jacques. Sistemas agrários en América Latina. México: FCE, 1994. CHOR MAIO \& VILLAS BOAS, Gláucia (orgs.). Ideais de modernidade e Sociologia no Brasil (Ensaios sobre Luiz de Aguiar Costa Pinto). Porto Alegre: Editora da Universidade - UFRGS, 1999.

D’INCAO, Maria Ângela. História e Ideal: ensaios sobre Caio Prado Junior. São Paulo: Brasiliense / Ed. da UNESP, 1989.

D’INCAO, Maria Ângela. O Saber Militante: ensaios sobre Florestan Fernandes. Rio de Janeiro: Paz e Terra, 1987.

DANTAS MOTA, Lourenço (org.). Introdução ao Brasil: um banquete no trópico. São Paulo: Ed. SENAC, 3a ed. 2001.

DELICH J. Francisco. Tierra y conciencia campesina em Tucumán. Argentina: Ediciones Signos, 1970.

DELICH J. Francisco. Repensar América Latina. Barcelona: Gedisa, 2004. 
DÍAS MOTA, Laura \& CATTANI, Antonio David (coords.). Desigualdad, pobreza, exclusión y vulnerabilidad en América Latina. México, AUEM / ALAS/ UFRGS, 2004.

DOMINGUES, José Maurício. Criatividade social, subjetividade coletiva e a modernidade brasileira contemporânea. Rio de Janeiro: Contracapa, 1999.

DOMINGUES, José Maurício. Sociologia e modernidade: para entender a sociedade contemporânea. R. J: Civilização Brasileira, 1999.

DUPAS, G. Ética e Poder na Sociedade da Informação. São Paulo: UNESP, 2000. 135p.

DURAND, José C. G. (org.). Sociologia do Desenvolvimento. 2ª ed. Rio de Janeiro: Zahar, 1974.

ECHEVARRÍA, José Medina. Consideraciones sociológicas sobre el desarrollo económico. Buenos Aires: Solar-Hachette, 1964 (FLACSO, Santiago de Chile, 1959).

ECHEVERRÍA, Javier. Introdução à Metodologia da Ciência. Coimbra: Almedina, 2003.

FACULTAD DE CIENCIAS SOCIALES. El Proceso social de la Sociedad Uruguya en la segunda mitad del Siglo XX, según los Sociólogos. v. I, Montevideo: FCS Depto. De Sociología, Universidad de la Republica, 2000.

FALEIROS, Maria I. L. \& CRESPO, Regina A. Humanismo e Compromisso: ensaios sobre Octavio lanni. SP: Ed. da UNESP, 1996.

FALS BORBA, Orlando. El Reformismo Por Dentro Em América Latina. México: Siglo Veintiuno, 3ạ. Ed. 1976 (1972).

FALS BORBA, Orlando. Las revoluciones inconclusas em América Latina (18091968). 3ạ. Ed. México: Siglo Veintiuno, 1971 (1968).

FALS BORDA, Orlando \& CAMPOS, G. G. La violencia en Colombia. Bogotá: Printer, 1988.

FALS BORDA, Orlando. Acción y espacio: autonomias em la nueva Republica. Bogotá, IEPRI - Univ. Nacional / Tercer Mundo, 2000. 
FERNANDES, Florestan. A natureza sociológica da Sociologia. São Paulo: Ática, 1980.

FERNANDES, Florestan. A revolução burguesa no Brasil (ensaios de interpretação sociológica). Rio de Janeiro: Zahar, 1975.

FERNANDES, Florestan. A Sociologia no Brasil. Petrópolis: Vozes, 1977.

FERNANDES, Florestan. Ensaios de Sociologia Geral e Aplicada. São Paulo: Pioneira, 1960.

FERNANDES, Florestan. A Condição de Sociólogo. São Paulo: Hucitec,1978.

FERNANDES, Florestan. A Sociologia numa Era de Revolução Social. São Paulo: Nacional, 1976.

FERNANDES, Florestan. Fundamentos empíricos da explicação sociológica. 2.ed. São Paulo: Nacional, 1967.

FILGUEIRA, Carlos A. 25 anos de Sociologia uruguaia. In: CAMACHO, D. (org.). Debates sobre a teoria da dependência. São José da Costa Rica: Editorial Universitária Centroamericana, 1979. p. 591-638.

FIORI, J. C. Um novo país é possível. Entrevista. In: Caderno de Cultura ZH, Porto Alegre, 18/01/2003, p. 2-3.

FORACCHI, Marialice M. A participação social dos excluídos. São Paulo: Hucitec, 1982.

FORACCHI, Marialice M. O Estudante na Sociedade de Classes. São Paulo: Nacional, 1965.

FRANCO, Rolando. Veinticinco años de Sociología Latinoamericana: un balance. In: CAMACHO, 1979, p. 233-284.

FREIRE, Gilberto. Casa Grande e Senzala. 41aㅡ Edição. Rio de Janeiro: Record, 2000.(1’ Edição: 1933).

FREIRE, Gilberto. Sobrados e Mocambos. Rio de Janeiro: Record, 2000. 12ª ed. (1a Edição: 1936).

GARCIA Jr., Afrânio Raul. O Sul: caminho do roçado; estratégias de reprodução camponesa e transformação social. S. P.: Marco Zero; Brasília: Editora Universidade de Brasília; MCT-CNPQ, 1989. 
GARCIA, Sylvia G. Destino Ímpar: sobre a formação de Florestan Fernandes. São Paulo: Editora 34, 2002.

GERMANI, Gino. Política y sociedad en una época de transición. Buenos Aires: Paidós, 1959.

GERMANI, Gino. Política y sociedad en una época de transición. Buenos Aires, Paidós, 4⿳亠丷. Ed. 1971 (1959).

GERMANI, Ana Alejandra. Gino Germani: del antifascismo a la Sociología. Buenos Aires, Taurus, 2004.

GIARRACCA, Norma (ed.). La protesta social em la Argentina. Buenos Aires: Alianza, 2001.

GIARRACCA, Norma. Estudios Rurales. Argentina: La Colmena, 1999.

GIARRACCA, Norma. Uma Nueva Ruralidad Em América Latina. Argentina: Clacso, 2001.

GNACCARINI, José César. Latifúndio e Proletariado. São Paulo: Polis, 1980.

GODOY URZÚA, Hernan. El desarrollo de la Sociologia en Chile. In: CAMACHO, 1979, p. 507-638.

GOMEZ, Sergio \& ECHENIQUE, Jorge. La agricultura chilena: lãs dos caras de la modernización. Santiago de Chile: FLACSO / AGRARIA, 1988.

GÓMEZ, Sergio E. La "Nueva Ruralidad": Qué tan nueva ? Chile: Lom Ediciones, 2002.

GONZÁLES CASANOVA (coord.). Ciencias Sociales: algunos conceptos básicos. México: Siglo XXI, 2ª ed. 1999.

GONZÁleS CASANOVA (coord.). Historia Política de los Campesinos Latinoamericanos. México: Siglo XXI, V. 1, 1984; V. 2, 1985; V. 1985; V. 4, 1985.

GONZÁLES CASANOVA, Pablo. Las nuevas ciencias y las humanidades: de la Academia a la Política. Barcelona: Anthropos; México: UNAM, 2004.

GONZÁlez CASANOVA, Pablo. A Democracia no México. Rio de Janeiro: Civilização Brasileira, 1967 (México, Era, 1965). 
GRACIARENA, Jorge. O Poder e as Classes Sociais no Desenvolvimento da América Latina. São Paulo: Mestre Jou, 1971 (1967).

GRUPO DE INVESTIGACAIONES AGRARIAS. La Agricultura latinoamericana: Crisis, Transformaciones y Perspectivas. Chile: GIA / CLACSO, 1991.

GUADILLA, C.G. Complejidades de la Globalizacion y la Comercialización de la Educacion Superior - reflexiones para el caso de América Latina. Porto Alegre: 1a Conferência Regional Latinoamericana del Foro UNESCO sobre Educación Superior, Investigación y Gestión, 1 a 3 de setembro, ILEA-UFRGS (mimeo). 2004.

HALPERIN DONGHI, Túlio. Historia contemporânea de América Latina. 6a ed. Buenos Aires / Madrid: Alianza, 1994.

HASSAM, M. Disparidades Norte-Sul na produção e uso do conhecimento. In: Jornal da Ciência, Rio de Janeiro, n. 408, 19 de março de 1999.

HIRANO, Sedi. Castas, estamentos e classes sociais. $3^{\underline{a}}$ ed. revista. Campinas: UNICAMP, 2002.

HOBSBAWM, Eric. A Era dos Extremos. Rio de Janeiro: Paz e Terra, 1994; The Age of Extremes (A History of the word - 1914-1991). New York: Pantheon Books, 1994.

HOBSBAWM, Eric. Tempos Interessantes: uma vida no Século XX. São Paulo: Companhia das Letras, 2002.

IANNI, Octavio. Sociologia da Sociologia. São Paulo: Ática, 1989.

IANNI, Octavio. Sociologia e Sociedade no Brasil. São Paulo: Alfa-Omega, 1975. IANNI, Octavio (org.). Florestan Fernandes. São Paulo: Ática, 1986.

IANNI, Octavio. Origens agrárias do estado brasileiro. Rio de Janeiro: Civilização Brasileira, 1984.

IANNI, Octavio. A Era do Globalismo. Rio de Janeiro: Civilização Brasileira, 1996. IANNI, Octávio. A Idéia de Brasil Moderno. S. P.: Brasiliense, 1992.

IANNI, Octavio. A luta pela terra: história social da terra e da luta pela terra numa área da Amazônia. Petrópolis: Vozes, 1978. 
IANNI, Octávio. A Sociedade Global. Rio de Janeiro: Civ. Brasileira, 1992.

IANNI, Octavio. Capitalismo, violência e terrorismo. R.J.: Civilização Brasileira, 2004.

IANNI, Octavio. Colonização e contra-reforma agrária na Amazônia. Petrópolis: Vozes, 1979.

IANNI, Octavio. El Estado capitalista em la época de cárdenas. México: ERA, 1977.

IANNI, Octavio. Enigmas da Modernidade - Mundo. R.J.: Civilização Brasileira, 2000.

IANNI, Octavio. O colapso do populismo. Rio de Janeiro: Civilização Brasileira, 1968.

IANNI, Octavio. O labirinto latino-americano. Petrópolis: Vozes, 1993.

IANNI, Octavio. Raças e Classes Sociais no Brasil. 3ำ ed. São Paulo: Brasiliense, 1987.

IANNI, Octavio. Sociologia da Sociologia Latino-americana. Rio de Janeiro: Civilização Brasileira, 1971.

JORRAT, Jorge R. \& SAUTU, Ruth. Despúes de Germani: exploraciones sobre estructura social de la Argentina. Buenos Aires, Paidós, 1992.

JOSEPH A. Jaime. La ciudad, la crisis y las salidas. Lima: Fac. de Ciencias Sociales, UNM San Marcos, 2005.

LANDER, Edgardo. La colonialidad del saber: eurocentrismo y ciencias sociales, perspectivas latinoamericanas. Buenos Aires: CLACSO, 2003.

LEAL Y FERNÁNDEZ, Juan Felipe et alii. La Sociología Contemporánea en México. México: Facultad de Ciencias Políticas y Sociales de la UNAM, 1994.

LECHNER, Norbert. Os novos perfis da política: um esboço. Revista Nueva Sociedad, n. 130, marzo-abril. 1994 (edição brasileira em: Revista LUA NOVA. São Paulo, CEDEC, 2004).

LECHNER, Norbert. Las sombras del mañana (la dimensión subjetiva da política). Santiago de Chile: LOM, 2002. 
LECHNER, Norbert. Los patios interiores de la democracia. Santiago de Chile: FLACSO, 1988.

LEÓN LOPEZ, Arturo et alii. Cultura e identidad en el campo latinoamericano. Xochimilco, México: ALASRU / Univ. Aut. Metropolitana, 1999.

LIEDKE Filho, Enno. Sociologia Brasileira: tendências institucionais e epistemológico-teóricas contemporâneas. Sociologias, Porto Alegre, ano 5, n.9, p.216-245, jan./junho. 2003. Disponível em: <http://www.scielo.br>.

LIEDKE Filho, Enno. Teoria da dependência ou desenvolvimento da América Latina". In: VERMELHAS MIX, Miguel e PANIZZI, Wrana Maria (orgs.). Brasil de Porto Alegre. Porto Alegre: Editora da UFRGS, 2003. p. 163-180.

LIEDKE Fo,Enno. Sociologia Brasileira: tendências institucionais e epistemológicoteóricas contemporâneas. Sociologias, Porto Alegre, ano 5, no 9, p. 216-245, jan/ jun. 2003.

LIPPI OLIVEIRA, Lúcia. Ás Ciências Sociais não Rio de Janeiro. In: MICELI, Sérgio (org.) História da Ciências Sociais não o Brasil. V. 2. São Paulo: FAPESP/Sumaré, 1995. p. 233-307.

LIPPI OLIVEIRA, Lucia. A Sociologia do Guerreiro. Rio de Janeiro: Ed. UFRJ, 1995. MARIATEGUI, Jose Carlos. 7 Ensayos de interpretación de la realidad peruana. Lima: Amauta, 27ํㅡ ed. 1973

MARINI, Rui Mauro \& E MILLÁN, Márgara (coords.). La Teoría Social Latinoamericana: cuestiones contemporáneas. México: UNAM, Tomo IV, 1996.

MARINI, Rui Mauro \& MILLÁN, Márgara (coords.). La Teoría Social Latinoamericana: los orígenes. México, UNAM, Tomo I, 1994.

MARINI, Rui Mauro \& MILLÁN, Márgara (coords.). La Teoría Social Latinoamericana: subdesarrollo y dependendia. México, UNAM, Tomo II, 1994.

MARINI, Rui Mauro \& MILLÁN, Márgara (coords.). La Teoría Social Latinoamericana: la centralidad del marxismo. México, UNAM, Tomo III, 1995.

MARINI, Rui Mauro. Acerca de la reforma del Estado en América Latina. In: SUÁREZ, 1992, p. 177-183). 
MARTI, Jose. Nuestra America. Buenos Aires: Losada, 1980.

MARTINEZ PELÁEZ, Severo. La Pátria del Criollo - ensayo de interpretación de la realidad colonial guatemalteca. México: FCE, 2ae ed. 1998.

MARTINS, José de Souza. Os camponeses e a política no Brasil. Petrópolis: Vozes, 1981.

MARTINS, José de Souza. Caminhada no chão da noite. São Paulo: Hucitec, 1989.

MARTINS, José de Souza. A sociabilidade do homem simples. São Paulo: Hucitec, 2000. São Paulo: Paulus, 1997.

MARTINS, José de Souza. A Sociedade vista do abismo (novos estudos sobre exclusão, pobreza e classes sociais). Petrópolis: Vozes, 2002.

MARTINS, José de Souza. Expropriação e Violência: a questão política no campo. 3.ed. São Paulo: Hucitec, 1991.

MARTINS, José de Souza. Florestan: Sociologia e Consciência Social no Brasil. São Paulo: EDUSP, 1998.

MARTINS, José de Souza. Fronteiras. São Paulo, HUCITEC, 1998.

MARTINS, José de Souza. O Poder do Atraso (ensaios de Sociologia da História Lenta). São Paulo: Hucitec, 1994.

MATTOS, Sergio Sanandaj \& MATO GROSSO, Lejeune. Sociólogos \& Sociologia. História das suas Entidades no Brasil e no Mundo. São Paulo: ASESP, 2005.

MAZZEI, Enrique (comp.). El Uruguay desde la Sociología. Montevideo: Departamento de Sociología, Facultad de Ciencias Sociales, Universidad de la República, 2003.

MEDEIROS, Leonilde Sérvolo de. História dos movimentos sociais no campo. Rio de Janeiro: FASE, 1989.

MICELI, Sérgio (org.). História das Ciências Sociais no Brasil. São Paulo: Sumaré, 1995. Volume II.

MICELI, Sérgio (org.). História das Ciências Sociais no Brasil. São Paulo: Vértice, 1989. Volume I. 
MICELI, Sérgio (org.). O que ler na Ciência Social Brasileira (1970-1995). São Paulo: ANPOCS / Sumaré, 1999. Volume II.

MICELI, Sérgio (org.). O que ler na Ciência Social Brasileira (1970-2002). S. P.: ANPOCS / Sumaré, 2002. Volume IV.

MINUJIN, Alberto. Cuesta abajo: efectos de la crisis en la sociedad argentina. Buenos Aires: UNICEF / Losada, 3aㅡ ed. 1995 (1992).

MOTA, Carlos G. Ideologia da Cultura Brasileira (1933-1974). São Paulo: Ática, 1980.

MURMIS, Miguel \& PORTANTIERO, Juan Carlos. Estúdios sobre los orígenes del peronismo. 3a ed. Buenos Aires: Siglo Veintiuno, 1974 (1971).

NOGUEIRA, Oracy. Pesquisa Social. São Paulo: Nacional, 1968.

OBSERVATÓRIO Social de América Latina. Buenos Aires: CLACSO, revista desde 2000.

OLIVER COSTILHA, Lucio (coord.). Balance y perspectivas del pensamiento latinoamericano. México: ALAS / Universidad de Colima,1996.

QUIJANO, Anibal. Colonialidad del poder, eurocentrismo y América Latina. In: LANDER, Edgardo. La colonialidad del saber: eurocentrismo y ciencias sociales, perspectivas latinoamericanas. Buenos Aires: CLACSO, 2003. p. 201-246.

PAVARINI, Massimo \& PEGORARO, Juan. El control social en el fin del siglo. Buenos Aires: UBA, 1995.

PEREIRA DE QUEIROZ, Maria Isaura. O campesinato brasileiro. Petrópolis: Vozes, 1973.

PEREIRA DE QUEIROZ, Maria Isaura. O messianismo no Brasil e no mundo. 2 ${ }^{a}$ ed. São Paulo: Alfa-Omega, 1976.

PEREIRA, Luiz. Ensaios de Sociologia do Desenvolvimento. São Paulo: Pioneira, 1970.

PEREIRA, Luiz. Ensaios sobre o Brasil Contemporâneo. São Paulo: Pioneira, 1971. PÉREZ CORREA, Edelmira. La nueva ruralidad en América Latina. Bogotá: Maestria 
en Desarrollo Rural, Pontificia Universidad Javeriana, 2001.

PIERUCCI, Antonio Flávio. Ciladas da diferença. São Paulo: Ed. 34, 1999.

PINHEIRO, Paulo Sérgio (ed.). S. P. sem medo: um diagnóstico da violência urbana. R. J.: Garamond, 1998.

PINHEIRO, Paulo Sérgio et alii. Crime, Violência e Poder. S. P.: Brasiliense, 1983. PINHEIRO, Paulo Sérgio et alii. A violência brasileira. S. P.: Brasiliense, 1982.

PINHEIRO, Paulo Sérgio et alii. Democracia, Violência e Injustiça. R. J.: Paz e Terra, 2000.

PIÑEIRO, Diego. 30 Años de Sociologia rural en América Latina. Uruguay, 2000. SBS/ALASRU.

PIÑEIRO, Diego. Los trabajos de la Sociologia. Montevideo: CIESU,1988.

PRADO JR. Caio. Evolução Política do Brasil. São Paulo: Brasiliense, 1972 (1ª ed. 1933).

PRADO JR. Caio. A Revolução Brasileira. São Paulo: Brasiliense, 1972.

PRADO JR. Caio. Formação do Brasil Contemporâneo. 14ạ ed. São Paulo: Brasiliense, 1976. (1ํ- Edição: 1942).

PRADO JR. Caio. História Econômica do Brasil. 19ª ed. São Paulo: Brasiliense, 1976. (1a Edição: 1945).

PRECIADO C. , Jaime et alii. Criminalización de los poderes, corrupción y tráfico de drogas. Guadalajara: Centro de Ciencias Sociales y Humanidades, Universidad de Guadalajara, 2004.

RAMONET, I. El Consenso de Porto Alegre. Madrid, El País, 12 febrero 2001. Disponível em: <www.elpais.es/articulo.html>.

RAMOS, Guerreiro. A Redução Sociológica. Rio de Janeiro: Tempo Brasileiro, 1965 (1958), ed. no México.

REGO, Rubem Murilo Leão. Sentimento do Brasil: Caio Prado Jr. Campinas: Ed. UNICAMP, 2000. 
REVISTA SOCIOLOGIAS. Porto Alegre, Revista do PPG - Sociologia do IFCH UFRGS, 1999-2004, Volumes 1 a 14. Disponível em: <www.scielo.com.br>.

REVISTA DELITO Y SOCIEDAD. Buenos Aires / Santa Fe, UBA / Un. del Litoral, n. 1 a $18-19$.

RIBEIRO TORRES, Ana Clara. El Rostro Urbano De América Latina. Buenos Aires: CLACSO, 2004.

RICARDO, Cassiano. Marcha para o Oeste. 4a ed. São Paulo: José Olympio / EDUSP, 1970. (1ª Edição: 1940).

RIOS BURGA, Jaime R. La Sociología en San Marco. Lima: UNMSM, 2001.

ROMERO SALAZAR, Alexis (ed.). La sociología Venezolana hoy. Venezuela: Asociación Venezlana de Sociología / La Universidad de Zulia, 2001.

SADER, Emir (org.). Democracia sin exclusiones ni excluídos. Caracas:. Editorlal Nueva Sociedad / ALAS / CLACSO / UNESCO, 1998.

SAFFIOTI, Heleieth I. B. A mulher na sociedade de classes: mito e realidade. São Paulo: Quatro Artes, 1969.

SALINAS, Darío F. (coord.). Problemas y perspectivas de la democracia em América Latina. México: ALAS / Univ. Iberoamericana / Triana, 1999.

SALINAS, Dario F. \& JIMENEZ C. Edgar (coords.). Gobernabilidad y globalización: procesos políticos recientes en América Latina. México, Gernika, 2002.

SALLES, Severo et alii. Balance y perspectivas de los estudios latinoamericanos. México: Cuadernos de Estudios Latinoamericanos, Facultad de Ciencias Políticas y Sociales, UNAM, 1985.

SÁNCHES RAMOS Y SOUSA ELÍZAGA (coords.). América Latina: los desafíos del pensamiento crítico. México: Siglo XXI, 2004.

SANTOS, Theotonio dos. Do Terror à Esperança. São Paulo: Idéias \& Letras, 2004.

SARMIENTO, Domingo Faustino. Facundo o Civilización y Barbarie. Buenos Aires: Espasa Calpe, 1994.

SCHERER-WARREN, Ilse \& KRISCHKE, Paulo J. (org.). Uma revolução no cotidiano? Os novos movimentos sociais na América Latina. S. P.: Brasiliense, 1987. 
SCRIBANO, Adrián. Una voz de muchas voces: accion colectiva y organizaciones de base. Córdoba: SERVIPROH, 2003.

SEGATTO, J. Antonio e AMAYO. (org.). J.C Mariátegui e o marxismo na América Latina. São Paulo: UNESP, 2002.

SEOANE, José \& TADDEI, Emilio. Resistências Mundiales. Buenos Aires: CLACSO, 2001.

SEOANE, José (comp.). Movimientos sociales y conflicto en América Latina. Buenos Aires: CLACSO, 2003.

SIERRA, Geronimo. Los Rostros Del Mercosur. Buenos Aires: Clacso, 2001

SOBRAL FONSECA, Fernanda \& PORTO GROSSI, Maria. A Contemporaneidade Brasileira. Santa Cruz do Sul: Unisc, 2001

SONNTAG, Heinz R. \& BRICEÑO-LEÓN, Roberto (eds.). Pueblo, época y desarrollo: la sociología de América Latina. Venezuela: Nueva Sociedad, 1998.

SOSA ELÍZAGA, Raquel (coord.). América Latina y el Caribe: perspectivas de su reconstrucción. México: UNAM / ALAS, 1996.

SOSA ELÍZAGA, Raquel (coord.). Sujetos, víctimas y territorios de la violencia en América Latina. México: Universidad de la Ciudad de México, 2004.

SOUZA, Jessé. Patologias da Modernidade: um diálogo entre Habermas e Weber. S. P.: Annablume, 1997.

STAVENHAGEN, Rodolfo. Siete tesis equivocadas sobre América Latina: sociología y subdesarrollo. México, 1973, Nuestro Tiempo (no Brasil, in DURAND, 1974).

STRASSER, Carlos. Democracia \& Desigualdad. Buenos Aires: CLACSO, 2000.

SUÁREZ S. Luís. América Latina y el Caribe: medio siglo de crimen y impunidad (1948-1998). La Habana / Nafarroa - Navarra, Instituto Cubano del Libro / Zambon Iberoamericana, 2001.

SUÁREZ S. Luís. Estado, nuevo orden económico y democracia en América latina. Caracas: Nueva Sociedad, 1992.

TAVARES-DOS-SANTOS, José-Vicente Policía y seguridad ciudadana en Brasil. In: 
SIERRA, Jerónimo de \& BERNALES ALVARADO, Manuel. Democracia, Gobernanza y desarrollo en el MERCOSUR. Montevideo: UNESCO/CLACSO, 2004. p. 169173.

TAVARES-DOS-SANTOS, José-Vicente The World Police Crisis and the Construction of Democratic Policing. In: International Review of Sociology. Oxfordshire, Inglaterra: Taylor \& Francis, vol. 14, no 1, march 2004, p. 89-106.

TAVARES-DOS-SANTOS, José-Vicente Crisis de la Pos-modernidad en el siglo XXI: la falencia de la seguridad pública, la cuestión policial y la noción alternativa de Seuridad Ciudadana. In: PEGORARO, J. \& MUÑAGORRI, I. La Relación SeguridadInseguridad en Centros Urbanos de Europa y América Latina. Madrid: I. I. de Sociologia Jurídica de Oñati - ISA / Dykinson, 2004, p. 253-273.

TAVARES-DOS-SANTOS, José-Vicente Violências e dilemas do controle social nas sociedades da "modernidade tardia. Revista São Paulo em Perspectiva, São Paulo, Fundação SEADE, vol. 18, n. 1, p. 3-12, janeiro-março. 2004. Disponível em: $<$ www.scielo.com.br $>$.

TAVARES-DOS-SANTOS, José-Vicente. A Sociologia para o Século XXI: análise, responsabilidade e imaginação. In: BARREIRA, César (org.). A Sociologia no Tempo: memória, imaginação e utopia. São Paulo: Cortez, 2003. p. 195-213.

TAVARES-DOS-SANTOS, José-Vicente; BARREIRA, César; BAUMGARTEN, Maíra (orgs.). Crise Social e multiculturalismo (estudos de Sociologia para o Século XXI). São Paulo: HUCITEC, 2003.

TAVARES-DOS-SANTOS, José-Vicente. Violências, América Latina: a disseminação de formas de violência e os estudos sobre conflitualidades. Sociologias, Porto Alegre, v. 4, n. 8, p. 16-32, jun./dez. 2002. Disponível em: <www.scielo.com.br>.

TAVARES-DOS-SANTOS, José-Vicente. A violência na Escola, uma questão social global. In: BRICEÑO-LEÓN, Roberto (org.). Violência, Sociedad y Justicia em America Latina. Buenos Aires: CLACSO, 2002. p. 117-133.

TAVARES-DOS-SANTOS, José-Vicente. Microfísica da Violência, uma questão social mundial. Ciência e Cultura - Revista da SBPC, São Paulo, Ano 54, noo. 1, p. 22-24, julho. 2002.

TAVARES-DOS-SANTOS, José-Vicente. The Worldization of Violence and Injustice. Current Sociology, London, ISA - International Sociological Association / SAGE, v. 50, n. 1, p. 123-134, January. 2002.

TAVARES-DOS-SANTOS, José-Vicente. Conflitos agrários e violência no Brasil: agentes sociais, lutas pela terra e reforma agrária. In: PÉREZ CORREA, Edelmira. La nueva ruralidad en América Latina. Bogotá: Maestria en Desarrollo Rural, Pontificia Universidad Javeriana, 2001, p. 121-141. 
TAVARES-DOS-SANTOS, José-Vicente. A Violência na Escola: conflitualidade social e ações civilizatórias. Revista Educação e Pesquisa, São Paulo, v. 27, n. 1, p. 105-122, janeiro-julho. 2001.Disponível em: <www.scielo.com.br>.

TAVARES-DOS-SANTOS, José-Vicente. Violências em Tempo de Globalização. (Organizador, Autor da Introdução). São Paulo: Editora HUCITEC, 1999.

TAVARES-DOS-SANTOS, José-Vicente \& Gugliano, Alfredo (orgs.). A Sociologia para o Século XXI. Pelotas: EDUCAT, 1999.

TAVARES-DOS-SANTOS, José-Vicente (org.) As Revoluções Camponesas na América Latina. São Paulo: UNICAMP / ICONE / CLACSO, 1985.

THERBORN, Göran. Globalização e desigualdade: questões de conceituação e esclarecimento. Sociologias, Porto Alegre, v. 3, n.6, p.122-169, jun/dez. 2001. Disponível em: <www.scielo.com.br>.

TORRES-RIVAS, Edelberto (coord.). Historia General de centroamérica - Historia Inmediata (1979-1991). Madrid: FLACSO / Siruela, Tomo VI, 1993.

TORRES RIVAS, Edelberto. Acerca del pesimismo en las ciencias sociales. Guatemala, FLACSO, 2001.

TOURAINE, Alain. Palavra e sangue: Política e Sociedade na América Latina. São Paulo: Trajetória Cultural; Campinas: Ed. Univ. Est. Campinas, 1989.

TRAGTENBERG, Maurício. Memórias de um Autodidata no Brasil. São Paulo: Escuta, 1999.

VELOSO, Mariza \& MADEIRA, Angélica. Leituras Brasileiras: itinerários no pensamento social e na literatura. R.J.: Paz e Terra, 1999.

VERÓN, Eliseo. Imperialismo, lucha de clases y conocimiento (25 años de Sociologia en la Argentina). Buenos Aires: Tiempo Contemporâneo, 1974.

WAIZBORT, Leopoldo (ed.). A ousadia crítica: ensaios para Gabriel Cohn. Londrina: UEL, 1998.

WARMAN, Arturo. La historia de um bastardo: maíz y capitalismo. México: Fondo de cultura econômica, 1988.

WELTI, Carlos. Dinâmica demográfica y cambio social. México, PROLAP / ALAS, 1996.

ZEA, Leopoldo. El pensamiento latinoamericano. Barcelona: Ariel, 1976 (1965).

ZEBALLO, Eliseo \& SALINAS, Dario \& TAVARES-DOS-SANTOS, J.V. América Lati- 
na: Hacia una Nueva Alternativa de Desarrollo. Arequipa: Universidad San Agustin, 2005.

Recebido: 30/06/2005

Aceite final: 04/07/2005 


\section{Resumo}

O artigo aborda o papel desempenhado pela Sociologia na análise dos processos de transformação das sociedades latino-americanas, no acompanhamento do processo de construção do Estado e da Nação, na problematização das questões sociais na América Latina. São analisados seis períodos na Sociologia na América Latina e no Caribe: I) a herança intelectual da Sociologia ; II) a sociologia da cátedra; III) O período da "Sociologia Científica" e a configuração da "Sociologia Crítica"; IV) a crise institucional, a consolidação da "Sociologia Crítica" e a diversificação da sociologia; V) a sociologia do autoritarismo, da democracia e da exclusão; VI) a consolidação institucional e a mundialização da sociologia da América Latina (desde o ano de 2000), podendo-se afirmar que os traços distintivos do saber sociológico no continente foram: o internacionalismo, o hibridismo, a abordagem crítica dos processos e conflitos das sociedades latino-americanas e o compromisso social do sociólogo.

Palavras-chave: Sociologia na América Latina, Sociedades latino-americanas, Associação Latino-americana de Sociologia. 


\section{Sociology's contribution in Latin America to sociological imagination: analysis, critique, and social commitment}

\section{José Vicente Tavares dos Santos e Maíra Baumgarten}

The article focuses on the role played by Sociology in the analysis of processes of change in Latin American societies, in the process of construction of Nation and State, in the debate of social issues in Latin America and the Caribbean. Six periods in Sociology in Latin America and the Caribbean are examined: I) sociology's intellectual legacy; II) sociology as a cathedra; III) the period of "Scientific Sociology"; IV) the institutional crisis, the consolidation of "Critical Sociology", and the diversifying of sociology; $\mathrm{V}$ ) sociology of authoritarianism, democracy and exclusion; VI) institutional consolidation and globalization of Latin American sociology (since 2000). It may be said that the distinctive features of sociological knowledge in the continent were: internationalism, hybridism, the critical approach to processes and conflicts of Latin American societies, and the sociologist social commitment.

Key words: Sociology in Latin America, Latin American societies, Latin American Sociology Association. 